\title{
Role of glioblastoma stem cells in cancer therapeutic resistance: a perspective on antineoplastic agents from natural sources and chemical derivatives
}

Ana Laura V. Alves ${ }^{1 \dagger}$, Izabela N. F. Gomes ${ }^{1 \dagger}$, Adriana C. Carloni ${ }^{1}$, Marcela N. Rosa ${ }^{1}$, Luciane S. da Silva ${ }^{1}$, Adriane F. Evangelista', Rui Manuel Reis ${ }^{1,2,3}$ and Viviane Aline O. Silva ${ }^{{ }^{*}}$

\begin{abstract}
Glioblastoma (GBM) is the highest-grade form of glioma, as well as one of the most aggressive types of cancer, exhibiting rapid cellular growth and highly invasive behavior. Despite significant advances in diagnosis and therapy in recent decades, the outcomes for high-grade gliomas (WHO grades III-IV) remain unfavorable, with a median overall survival time of 15-18 months. The concept of cancer stem cells (CSCs) has emerged and provided new insight into GBM resistance and management. CSCs can self-renew and initiate tumor growth and are also responsible for tumor cell heterogeneity and the induction of systemic immunosuppression. The idea that GBM resistance could be dependent on innate differences in the sensitivity of clonogenic glial stem cells (GSCs) to chemotherapeutic drugs/radiation prompted the scientific community to rethink the understanding of GBM growth and therapies directed at eliminating these cells or modulating their stemness. This review aims to describe major intrinsic and extrinsic mechanisms that mediate chemoradioresistant GSCs and therapies based on antineoplastic agents from natural sources, derivatives, and synthetics used alone or in synergistic combination with conventional treatment. We will also address ongoing clinical trials focused on these promising targets. Although the development of effective therapy for GBM remains a major challenge in molecular oncology, GSC knowledge can offer new directions for a promising future.
\end{abstract}

Keywords: Chemoradioresistance, Clinical trials, Glial stem cell, Initiating cells, Therapeutic strategies, Natural products

\section{Introduction}

Gliomas are the most frequent primary brain tumors in adults, accounting for more than $80 \%$ of all malignant cerebral neoplasms [1]. Among these tumors, glioblastoma (GBM) is the most common primary intracranial tumor with a very poor prognosis (WHO grade IV), representing $57.3 \%$ of all gliomas $[1,2]$. These tumors

\footnotetext{
*Correspondence: vivianeaos@gmail.com

${ }^{+}$Ana Laura V. Alves and Izabela N. F. Gomes contributed equally to this work. ${ }^{1}$ Molecular Oncology Research Center, Barretos Cancer Hospital, Rua Antenor Duarte Villela, 1331, CEP 14784 400, Barretos, São Paulo, Brazil

Full list of author information is available at the end of the article
}

can be divided into $I D H$ wild type, clinically defined as primary or de novo glioblastoma, which corresponds to approximately $90 \%$ of GBM cases and generally occurs in patients aged 62 or older, and IDH mutant, corresponding to secondary glioblastoma (approximately 10\% of cases) that progressively develops from low-grade astrocytoma and frequently manifests in patients aged 4050 years old (Fig. 1) [2, 3]. Currently, the most frequent molecular alterations associated with primary GBM are epidermal growth factor $(E G F R)$ amplification or mutation, loss of heterozygosity $(\mathrm{LOH})$ of chromosome $10 \mathrm{q}$ at the phosphatase and tensin homolog (PTEN) locus, 


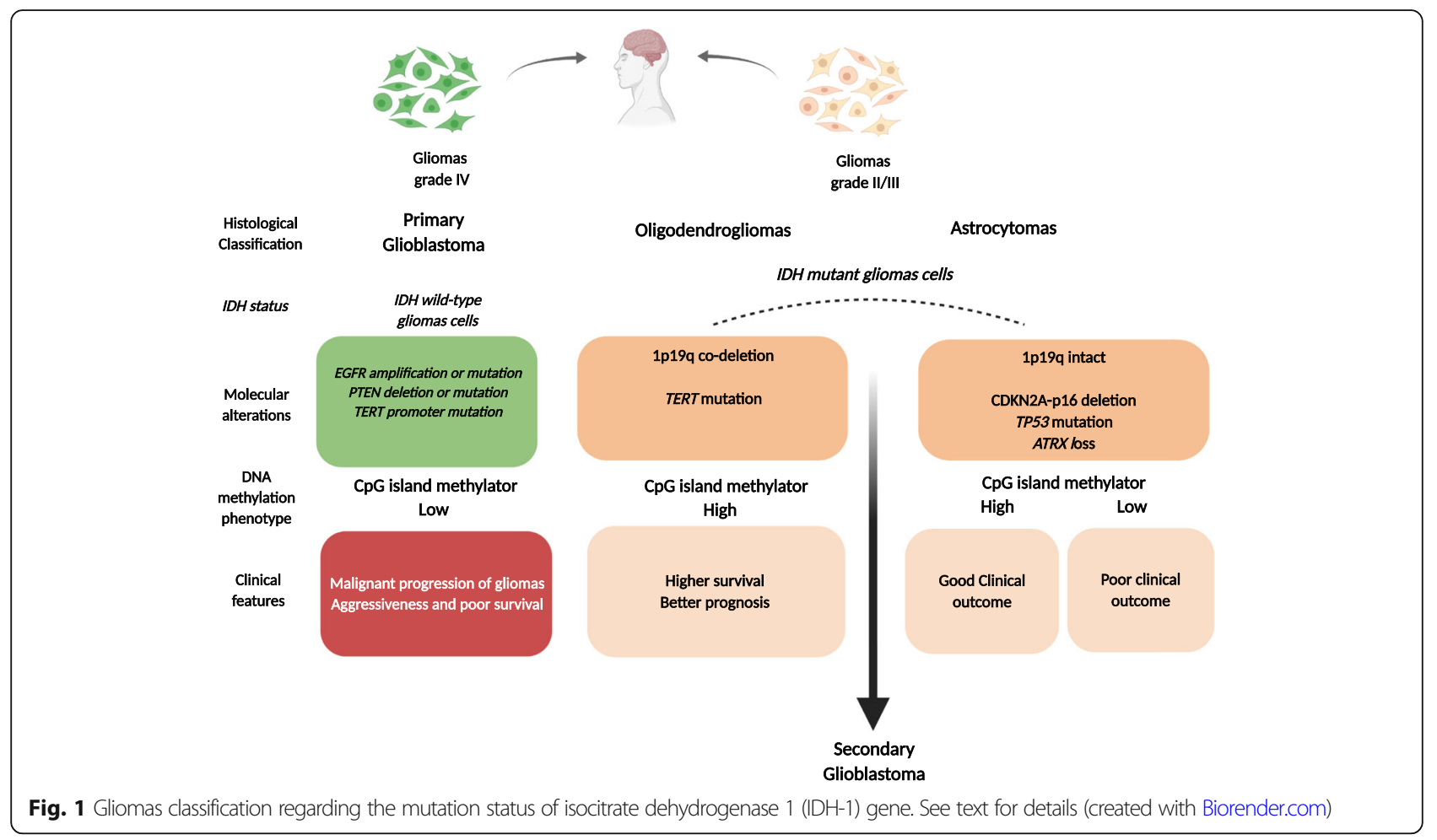

and TERT gene promoter mutation (Fig. 1). Moreover, combined deletion of the complete $1 p$ and $19 q$ after unbalanced translocation between chromosomes 1 and 19 resulting in the $1 p 19 q$ codeletion, homozygous deletion of CDKN2A-p16, loss of tumor suppressor genes such as TP53 and ATRX, and IDH1/2 gene mutations are common molecular alterations found in secondary GBM (Fig. 1) [2, 4]. The amplification of the EGFR gene affects the development and progression of gliomas, conferring more aggressive properties, and can be used as a therapeutic target (Fig. 1) [3, 5]. Recent studies showed that the TERT promoter mutation essentially accounted for primary GBM and was associated with aggressiveness and poor survival (Fig. 1) [6,7]. Although the presence of the $1 p 19 q$ codeletion is associated with higher survival [8], CDKN2A-p16 deletion was associated with poor prognosis [8]. The association of TP53 mutation in GBM and ATRX mutation has not been consistent. So far, it is known that both can co-occur [9]. Importantly, $I D H$ mutations are well-established markers of better prognosis [3, 8]. Genomic studies have also described five molecular subclasses (mesenchymal, classical (or proliferative), proneural, neural, and G-CIMP) [10]. Despite improvements in the knowledge and molecular characterization of glioblastomas, no significant difference in patient survival has been observed between primary and secondary glioblastomas, with both showing a mean survival of 12 to 15 months and a high frequency of tumor relapse [11].
The gold standard treatment for GBM patients is surgical resection combined with radiotherapy and adjuvant chemotherapy with the alkylating agent temozolomide (TMZ) $[3,12]$. Although some molecular features have been proposed as predictive biomarkers of the treatment response to alkylating agents, such as the methylation status of the O6-methylguanine-DNA-methyltransferase (MGMT) promoter, the clinical utility of these markers is minimal $[12,13]$. Some reasons proposed for this resistance may include the diffuse infiltrative nature to the surrounding brain, which hinders total resection; the high heterogeneity of GBM, involving distinct molecular pathways; and, more recently, the presence of stem celllike tumorigenic features, including inducing angiogenesis, uncontrolled cellular proliferation, resisting cell death, and genome instability and mutation $[3,12]$.

Evidence of small populations of tumor cells that are similar to stem cells, known as cancer stem cells (CSCs) or tumor-initiating cells, has been known as a cause of tumor initiation and development since the nineteenth century and was first described in hematologic malignancies in 1994 [14].

The first evidence of brain stem cells was shown by Ignatova et al. [15] and later supported by several other groups [16-18]. In glioblastoma, glioblastoma stem cells (GSCs) were first identified by Singh et al. as a population of cells capable of initiating tumor growth in vivo [19]. The first accepted GSC surface marker was CD133 [18]. This marker allows the subdivision of stem cells 
into two groups: CD133-positive cells $\left(\mathrm{CD} 133^{+}\right)$, or cancer stem cells, and CD133-negative cells $\left(\mathrm{CD} 133^{-}\right)$, or non-cancer stem cells [20]. CD133 expression also enables the characterization of cell self-renewal capacity, as there is a decrease in the expression of this surface marker during cell differentiation [21]. Another critical feature of $\mathrm{CD}_{133^{+}}$cells is the capacity to generate neurospheres in vitro and induce brain tumor formation in in vivo models $[19,22]$. Other markers have also been associated with GSCs that together classify a signature of these cells. According to Dirks and coworkers, CD15 and CD133 are the most useful surface markers of GSCs reported to date and stand out compared to other markers [23]. The presence of dual $\mathrm{CD} 133^{+} / \mathrm{Ki}-67^{+}$cells and associated Nestin or HOX genes is an adverse prognostic factor for GBM progression [24-26]. Another marker highly expressed in GSCs is the CXCR4 chemokine receptor (CD184), which is associated with $\mathrm{CD} 133^{+}$ cells and increased expression of hypoxia-inducible factor $(H I F-1-\alpha)[27,28]$. The same importance should be assigned to the MUSASHI-1 protein, a regulator of translation and cellular fate [29]. Other markers, including the cell-surface glycoprotein CD44; the cell-surface gangliosides A2B5, CD90, and SOX2; and ALDH1, L1CAM, KLF4, SALL4, and GFAP, have also been also used for the identification of GSCs [29-35]. However, the specificity of the surface marker CD133 remains unclear, with groups reporting the identification of GSCs that are CD133 negative [36]. Therefore, it is also noteworthy that although $\mathrm{CD} 133$ and $\mathrm{CD} 44$ persist on genetically diverse clones [37], the presence of more primitive markers, such as OCT-4, SALL4, and NANOG, among others, needs to be better defined and may be key to developing novel and effective treatments for GBMs [38]. The main biomarkers are summarized in Fig. 2.

Therefore, the promising GSC hypothesis offers new insight into cancer diagnosis and adds complexity in the management of brain tumors. The concept that GBM resistance could be dependent on innate differences in the sensitivity of clonogenic GSCs to chemotherapeutic drugs/radiation stimulated the scientific community to rethink the understanding of GBM growth and therapies designed to be directed at eliminating these cells or modulating their stemness [31, 39]. So far, the research strategies involve the development of drugs that target cancer stemness, directly or indirectly, in order to target multiple molecules, either alone or in combination.

This review aims to report intrinsic and extrinsic mechanisms that mediate chemoradioresistance in GSCs and therapies based on antitumor agents from natural sources, derivatives, and synthetics used alone or in synergistic combinations with conventional treatments. We will also summarize ongoing clinical trials focused on these promising targets. Although the development of effective therapies for GBM remains a major challenge
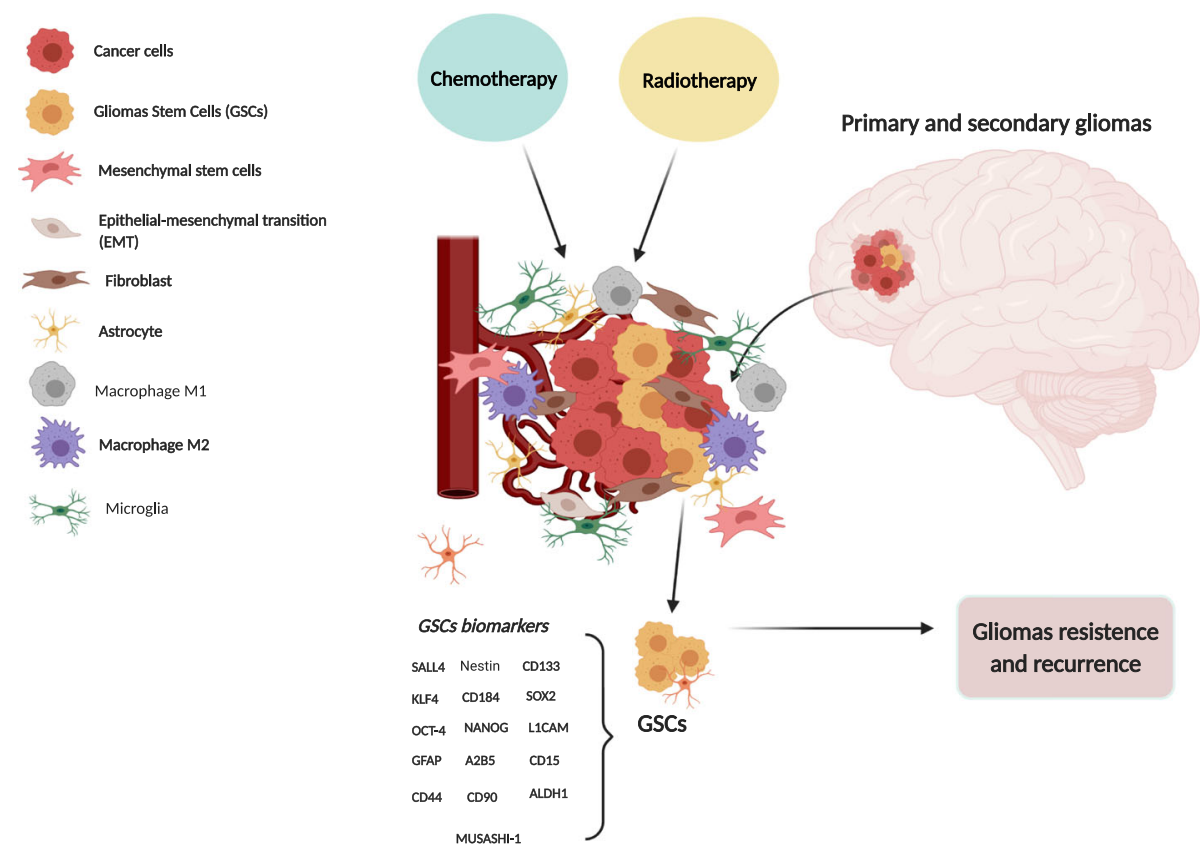

Fig. 2 Schematic overview of the cellular components of the microenvironment of glioblastoma (GBM). GSC: glial stem cell; Tumor microenvironment is a complex network composed of stromal cells (fibroblasts, microglia, astrocyte), mesenchymal cells, stem cells, and immune and inflammatory cells (macrophages). The main biomarkers of glial stem cells are indicated (created with Biorender.com) 
in molecular oncology, GSC knowledge can offer new directions for a promising future.

\section{Radioresistance}

Role of repair mechanism in mediating radioresistance Ionizing radiation (IR) from radiotherapy induces different types of DNA damage, especially DNA doublestrand breaks (DSBs). Depending on the type of injury caused, DNA repair mechanisms and DNA damage checkpoints can be triggered, allowing cells to repair DNA damage and proliferate again [40]. The cellular response to DNA damage has been considered as one of the leading survival mechanisms of tumor cells after radiotherapy [40, 41].

Preclinical evidence demonstrates that many of these protection mechanisms are activated in CSC populations, possibly resulting in treatment resistance [42]. Bao et al. showed that $\mathrm{CD} 133^{+}$cell subpopulations are resistant to IR due to a more efficient repair system (phosphorylation of CHK1, CHK2, and H2AX form $\gamma$-H2AX foci) than the bulk of tumor cells and undergo apoptosis less frequently [31]. Moreover, an increase in $\mathrm{CD}_{133^{+}}$ cells was also evidenced in clinical samples from recurrent tumors after high-dose radiotherapy treatment [43, 44]. Among other DNA repair-related genes, RAD51 overexpression is observed in GSCs, and BRCA1 and $B R C A 2$ showed upregulation in glioblastoma cell lines, which led to reduced DNA damage after irradiation [45, 46]. The activation of ataxia-telangiectasia mutated (ATM) and ATM- and Rad3-related (ATR) also mediates radioresistance $[47,48]$. In addition, other authors have reported that, in vitro, $\mathrm{CD} 133^{+}$primary cells are more radiosensitive than established glioma cell lines, with a reduced capacity to repair DNA double-strand breaks and an intact G2 checkpoint but no intra-S-phase checkpoint [21]. Therefore, the applicability of $\mathrm{CD} 133^{+} \mathrm{GBM}$ as a model of radioresistance is still unclear. These data highlight the heterogeneity of the in vitro radiosensitivity that exists among primary cell lines and reveal that radioresistance may be independent of the intrinsic GSC characteristics.

\section{Role of microenvironment in radioresistance}

One parameter that may influence radioresponse is the tumor microenvironment. Tumors are comprised of multiple components other than tumor cells (endothelial cells and multiple infiltrating inflammatory and immune cells, together with the extracellular matrix, cytokines, nitric oxide, and oxygen levels) which are also exposed to radiation during therapy, and their crosstalk might influence tumor stem cells' response to radiation [42, 49]. The critical role of the microenvironment, along with GSCs, is supported directly and indirectly by the observation that GSCs reside in specific niches, distinct compartmentalized regions that present morphologically and functionally distinct functions (Fig. 2) [50]. The stem cell niche plays an indispensable role in homeostasis, regeneration, maintenance, and repair. There are at least three specialized tumor niches in GBM that include the vasculature as an integral regulatory component, including the perivascular tumor niche, vascular-invasive tumor niche, and hypoxic-necrotic tumor niche. These niches are dependent not only on normal cell components in the tumor microenvironment but also on the genetic and epigenetic profiles of GSCs. The different combinations of cell components and functional statuses of the vasculature promote specific features and functions in the niches, as reviewed by Hambardzumyan and Bergers [50]. In addition to GSC maintenance, the niches could undergo dynamic alterations in a temporal and spatial manner and create a succession of tumor microenvironments to accommodate the aggressive growth of a tumor such as GBM into normal tissue, both during tumor progression and in response to therapeutic agents. In this context, some therapies could convert a tumor niche into another niche type instead of eliminating it, thereby losing their effectiveness. According to Hambardzumyan and Bergers, it is likely, for instance, that therapies such as radiation and cytotoxic chemotherapies, which create hypoxia and necrosis, may enhance hypoxic niches that will transition into perivascular tumor niches during tumor relapse [50]. Therefore, the understanding of the crosstalk between GSCs and their niches, which supports GSC self-renewal, tumor invasion, and metastasis, as well as GSC escape from therapy, has become a promising target. In this sense, Mannino and Chalmers proposed that radioresistance is a result of interactions between these cells and microenvironmental factors, i.e., the "microenvironment - stem cell unit" [51]. Brain hypoxia is known to be one of the most critical characteristics in the tumor microenvironment and is associated with the promotion of tumor progression and facilitation of angiogenesis, metabolism, and tumor radioresistance $[52,53]$, in addition to triggering mechanisms such as hypoxia-inducible factor (HIF) signaling and epithelial-mesenchymal transition (EMT). HIF signaling was also reported to be pivotal in GSC regulation [54]. Low oxygen levels were observed to prevent GSC differentiation, induce neurospheres, and maintain the potential of pluripotent embryonic and stemness markers $[55,56]$. The link between hypoxic responses and GSCs was suggested by $\mathrm{Li}$ and coworkers, who found a differential response of GSCs to the HIF family of transcription factors, including promotion of their self-renewal [57]. Likewise, a proof-of-concept study using HIF knockdown in GSCs resulted in reduced stemness in vitro and in vivo [57]. It has also been described that hypoxia induced the expression of vascular endothelial growth factor (VEGF) in HIF1- and 
HIF2-dependent GSCs [58]. A close relationship between $\mathrm{CD} 133^{+}$cells and vascular structures was also found in a study by Christensen and coworkers [59].

Moreover, two independent groups showed that the $\mathrm{CD}_{133^{+}}$subpopulation is capable of de novo tumor vascularization through direct differentiation into endothelial cells, suggesting that a therapy targeting angiogenic factors would be required to inhibit GBM stem cells and tumor neovascularization [60, 61]. Finally, it has also been shown that GBM cells irradiated under orthotopic conditions have a higher capacity for DSB repair than GBM cells irradiated in vitro, which resulted in the induction of fewer $\gamma \mathrm{H} 2 \mathrm{AX}$ and 53BP1 foci in $\mathrm{CD}_{133^{+}}$cells than in $\mathrm{CD}_{133^{-}}$cells [62]. The authors also showed an increase in the percentage of $\mathrm{CD} 133^{+}$ cells at 7 days after radiation, which persisted at the onset of neurologic symptoms, suggesting that $\mathrm{CD} 133^{+}$ cells are relatively radioresistant under intracerebral growth conditions [62].

\section{Role of autophagy in mediating radioresistance}

Autophagy is a conserved cellular process that is crucial for maintaining cellular homeostasis and survival and differentiation. Therefore, it is associated with a variety of pathologies [63]. In contrast to apoptosis, autophagy is a double-edged sword that could be either protective or detrimental to cells, depending on the nature of the stimulus (nutrient and growth factor deprivation or an external insult like radiation) and the extent of autophagy induction [64]. Recent studies suggest that autophagy has been recognized as frequently activated in cancer and mediates tumor cells' response to anticancer therapy, especially radiotherapy, decreasing its efficacy by contributing to GSC maintenance and reducing ROS-associated DNA damage $[65,66]$. Moreover, radiation preferentially activates autophagy in $\mathrm{CD}_{133^{+}}$cells and increases the levels of the autophagy-related proteins LC3, ATG5, and ATG12 [67]. The same was found in the radioresistant cell line, in which enhanced autophagic flux and silencing of the $L C 3 A$ gene sensitized mouse xenografts to radiation [68]. However, in a study examining the induction of autophagy by radiation and its role in the radioresistance of GSCs, the authors found that GSCs expressed lower levels of autophagy-related protein LC3 and radiation induced a low degree of autophagy in these cells [69]. Moreover, a recent study showed that autophagy induction by the mammalian targets of rapamycin (mTOR) inhibitor rapamycin triggers GSC differentiation and enhances their radiosensitization in vitro and in vivo, with rapamycin thus becoming a promising tool for radiosensitization in glioma [70,71].

\section{Chemoresistance}

Role of repair mechanism mediating chemoresistance

The resistance of GSCs to chemotherapeutic drugs has been well documented, yet the importance of DNA repair remains unclear. A recent study calls into question whether the differential and more efficient DNA repair system is specific to all CSCs, since the effects of TMZ require efficient DNA repair (mismatch repair system) [72, 73]. Moreover, the extensive heterogeneity within GBM can complicate the role of the DNA repair system in GSCs [72]. The DNA repair protein MGMT is the best-characterized repair protein and is a crucial modulator of TMZ chemoresistance in GBM [74-76]. MGMT is expressed in GBM at various levels, and reports of its expression in the GSC compartments remain conflicting [77, 78]. Nevertheless, there is consensus that MGMT expression substantially increases the resistance of GSC [77-79]. A recent report showed MGMT expression in half of the $\mathrm{CD}_{133^{+}}$cell lines tested, and the majority of these cell lines were resistant to TMZ. This result may suggest the presence of an alternative MGMTindependent mechanism of therapeutic resistance [80].

\section{Role of multidrug mediating chemoresistance}

Another mechanism involved in chemoresistance is multidrug resistance. However, its role in GSCs remains an open question. Normal and cancer stem cells have higher expression levels of several $\mathrm{ABC}$ transporters, which confer them with efflux ability for the fluorescent dye Hoechst 33342 and helps GBMs with the efflux of antineoplastic drugs [81]. In line with this, increased ABCG1 expression was reported in TMZ-induced cells (the side population cells in flow cytometry that present the GSC phenotype) [82], and enhanced expression of multidrug resistance 1 (MDR1) was found in the chemoresistant phenotype of $\mathrm{CD}_{133^{+}}$GSCs compared to bulk $C D 133^{-}[83,84]$. Although $A B C B 1$ can be an independent predictor for TMZ responsiveness [85], there is conflicting data regarding TMZ transport by these proteins. Bleu and coworkers showed that TMZ is not a substrate for the ABCG1 transporter [72, 86] in murine glioma cells.

On the other hand, $A B C G 2 / B C R P$ and $A B C B 1 / M D R 1$ overexpression in GSCs was correlated with higher resistance of GSCs to chemotherapeutic drugs. Accordingly, the use of an $\mathrm{ABC}$ transporter inhibitor, such as verapamil, can decrease temozolomide, doxorubicin, and mitoxantrone resistance in GSCs [87]. Besides, melatonin ( $N$-acetyl-5-methoxytryptamine) increased methylation levels of the $\mathrm{ABC}$ transporter $A B C G 2 / B C R P$ promoter, promoting a synergistic toxic effect with TMZ on GSCs and A172 malignant glioma cells [87]. Moreover, reversan, an inhibitor of the MRP1 protein, increased the sensitivity of primary and recurrent GBM 
cells to TMZ treatment; however, this effect has not yet been evaluated exclusively in GSCs [88].

\section{Role of apoptosis and autophagy in mediating chemoresistance}

The mechanisms of action of TMZ, such as apoptosis, senescence, and autophagy, have also been described in GSCs [72, 89]. Prolonged treatment with TMZ can induce p53 and p21WAF1/Cip1 and cell cycle arrest (G2/M arrest), although genetic background dependence is observed in GBM cell lines. Continued treatment also promotes apoptosis, but senescence is the major process observed in glioma and melanoma tumors or cell lines $[72,89,90]$. Concerning apoptosis, following TMZ exposure, higher expression levels of antiapoptotic genes were observed in GSCs than in differentiated cell lines, suggesting a possible link between GSC chemoresistance and antiapoptotic factors [84, 91]. It was also reported that drug resistance observed in GSCs might depend on abnormalities in the cell death pathway, such as the overexpression of antiapoptotic factors or silencing of key death effectors [92]. The autophagy process or autophagic cell death induction can also be observed in response to TMZ and contributes to glioma chemoresistance and TMZ treatment failure [93, 94].

Moreover, in GSCs obtained from freshly resected GBM specimens, the expression of autophagy-related proteins (i.e., Beclin-1, ATG55, and LC3) was decreased in $\mathrm{CD}_{133^{+}}$cells compared with $\mathrm{CD} 133^{-}$cells after TMZ exposure. The authors suggested that GSCs might not be susceptible to classical pathways of autophagy [95]. On the other hand, rapamycin induces the differentiation of GSCs by activating autophagy [96, 97]. Increased rates and numbers of neurospheres in the rapamycin group compared with other groups were also reported. Additionally, stem/progenitor cell and differentiation markers were downregulated and upregulated in rapamycin-treated cells, respectively [97]. These data suggest that apoptosis and autophagy might contribute to GSC chemoresistance.

\section{Role of Notch and Sonic hedgehog pathways in mediating chemoresistance}

The increased expression of proteins of the Notch and Sonic hedgehog (SHH) pathways in $\mathrm{CD}_{133^{+}}$cells compared with GBM cells has already been described [98]. The comparison between treated and non-treated $\mathrm{CD}_{133^{+}}$primary GBM cells showed upregulated expression of the NOTCH 1, NCOR2, HES1, HES5, and GLI1 genes after TMZ treatment, suggesting the increased activity of these pathways [99]. Moreover, the use of Notch or $\mathrm{SHH}$ inhibitors with TMZ reversed the resistance to TMZ [99].
Epithelial-mesenchymal transition (EMT) mediates GBM chemoresistance

The epithelial-mesenchymal transition process can also contribute to GBM chemoresistance. This was exploited through the gene $Z E B 1$, an EMT regulator, and a known regulator of stemness and SOX2 in solid tissue cancers [100]. In GBM, the overexpression of the ZEB1 gene induced the expression of $M G M T$, resulting in greater tumor chemoresistance and also induced the expression of SOX2 and OLIG2, resulting in greater stemness and higher capacity for tumor formation [101].

\section{Other mechanisms mediating chemoresistance-extrinsic pathways}

Previous studies reported that TMZ might eliminate CSCs under in vitro conditions [72, 77]. However, patients treated with TMZ, present no stabilized disease or recurrence, leading to fatal relapses [74], suggesting that other mechanisms, such as residual CSC survival, may occur in vivo. Other extrinsic factors, such as the microenvironment, contribute to the chemoresistance of solid tumors [72]. Hjelmeland and coworkers demonstrated that exposure to an acidic $\mathrm{pH}$ environment promoted malignancy in GBM through the induction of a GSC phenotype [102]. Moreover, cell-cell interactions and IL6 protein expression constitute indirect evidence suggesting that these mechanisms may be relevant for GSCs $[72,103]$. Several reports suggest that tumor cell stemness could be induced by tumor microenvironments such as hypoxia $[57,79,104]$ and drugs such as TMZ [80]. In line with this, tumor cells can acquire CSC properties $[80,105]$. A recent report showed essential data concerning the origin, development, and maintenance of the GSC population after TMZ treatment. In this study, the authors achieve the conversion of non-GSCs to GSCs, both in vitro and in vivo, after long-term exposure to clinically relevant doses of TMZ. They showed that newly formed GSCs expressed molecular markers associated with parental GSCs, displayed a high rate of tumor engraftment and had a more invasive phenotype. These data suggest that the stemness of GSCs may be governed by cellular plasticity and that TMZ can stimulate the dedifferentiation of non-GSCs, explaining the high rates of tumor recurrence after conventional therapy [80].

\section{Current strategies targeting cancer stem cells}

The discovery of pathways essential for modulating stemness properties has contributed to the identification of several molecules that could eliminate GSCs, including new antineoplastic agents from natural sources [106-113]. A summary of current potential treatments is presented in Table 1 and Fig. 3. 
Table 1 Summary of current therapeutic strategies for some natural products and their chemical derivatives in GSCs. The structure, biological targets, analysis methods, clinical phase andchanism of 38 natural compounds/or derivatives are described

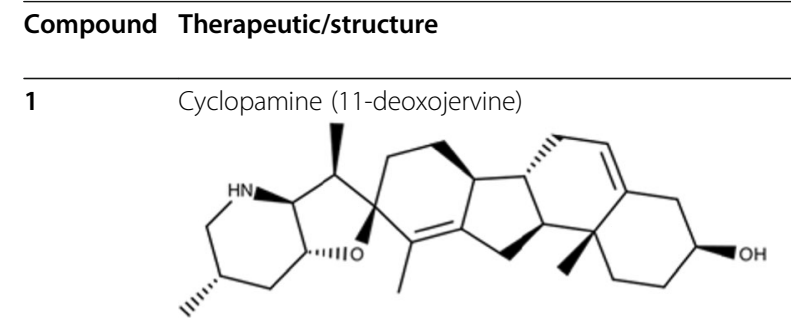

2

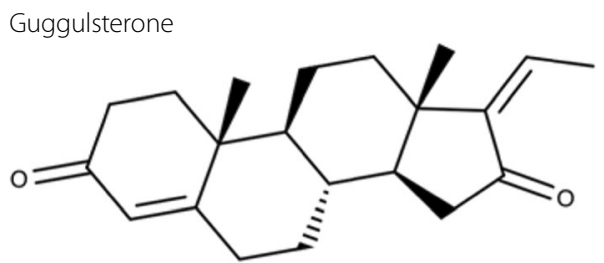

3

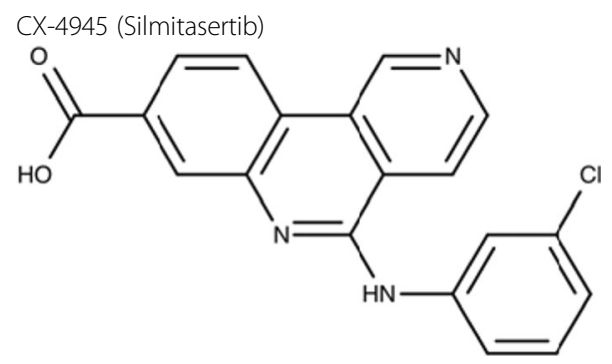<smiles>Cn1cc(-c2cnn3c(N)c(Br)c([C@@H]4CCCNC4)nc23)cn1</smiles>

5<smiles>C[C@H](CN(C)C)Oc1nc(Nc2cc3cccc(Cl)c3cn2)cnc1C#N</smiles>

6

AZD7762<smiles>NC(=O)Nc1cc(-c2cccc(F)c2)sc1C(=O)N[C@@H]1CCCNC1</smiles>

Biological targets/mechanism of action

Target Hedgehog pathway.

Promote inhibition of side and

aldefluor-positive populations.

Promote intrinsic apoptosis of GSCs

and sensitize cells to SANT-1.

Targeting Ros/NF-KB and Hedgehog.

In vitro

No

$[115,117]$

PubChem

CID:

6450278

Target several GSC factors and markers

Casein kinase 2 selective inhibitor.

In vitro

and

in vivo

Yes

[118-121]

CID:

24748573

DNA repair inhibitors

Promote radio-chemosensitivity.

Promote $\mathrm{CHK} 1$ inhibition.

$\begin{array}{lll}\text { In vitro } & \text { Yes } & \text { [122-125] } \\ \text { and } & & \text { PubChem } \\ \text { in vivo } & & \text { CID: }\end{array}$

46239015
DNA repair inhibitor

Promote CHK1 inhibition

DNA repair inhibitor

Promote radio-chemosensitivity.

Promote CHK1, CHK2, and ATM

protein inhibition.

$\begin{array}{lll}\text { In vitro } & \text { Yes } & {[124,125]} \\ \text { and } & & \text { PubChem } \\ \text { in vivo } & & \text { CID: } \\ & & 44203948\end{array}$

In vitro Yes $\quad[120,124]$

and PubChem

in vivo CID: 
Table 1 Summary of current therapeutic strategies for some natural products and their chemical derivatives in GSCs. The structure, biological targets, analysis methods, clinical phase andchanism of 38 natural compounds/or derivatives are described (Continued)

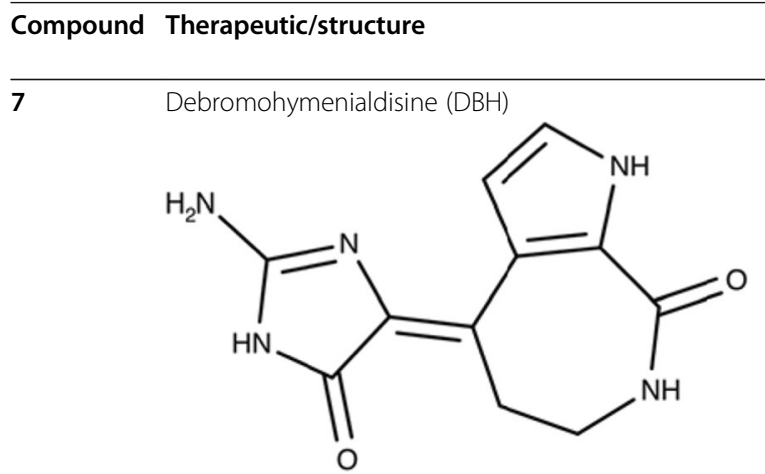

\begin{tabular}{llll}
$\begin{array}{l}\text { Biological targets/mechanism of } \\
\text { action }\end{array}$ & Evaluated & $\begin{array}{l}\text { Clinical } \\
\text { trials }\end{array}$ & Ref. \\
\hline DNA inhibitors & In vitro & Yes & {$[43,126-$} \\
Promote radio-chemosensitivity. & and & & $128]$ \\
Promote CHK1, CHK2, and ATM & in vivo & PubChem \\
protein inhibition. & & & CID: \\
& & & 135451156
\end{tabular}

8<smiles>C#Cc1cccc(Nc2ncnc3cc(OCCOC)c(OCCOC)cc23)c1</smiles>

9<smiles>COc1cc2ncnc(Nc3ccc(F)c(Cl)c3)c2cc1OCCCN1CCOCC1</smiles>

10

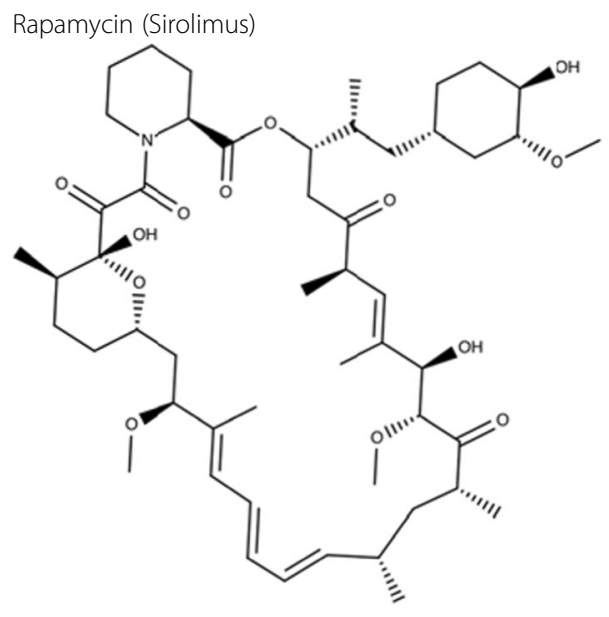

11<smiles>CCN(CC)CCCC(C)Nc1ccnc2cc(Cl)ccc12</smiles>

EGFR inhibitors

Promote proliferation and self-renewal inhibition.

Promote cell death.
In vitro Yes

and

in vivo

In vitro

EGFR inhibitors

Promote proliferation and self-renewal inhibition.

Promote cell death.

in vivo

In vitro

and

in vivo

Reduce stem cell markers.

Promote radiosensitivity.
[126-132]

PubChem

CID:

176870
Promote radiosensitivity Inhibit autophagy process.

$\begin{array}{lll}\text { In vitro } & \text { Yes } & {[124,136,} \\ \text { and } & & 137] \\ \text { in vivo } & \text { PubChem } \\ & \text { CID: } \\ & 2719\end{array}$


Table 1 Summary of current therapeutic strategies for some natural products and their chemical derivatives in GSCs. The structure, biological targets, analysis methods, clinical phase andchanism of 38 natural compounds/or derivatives are described (Continued)

\begin{tabular}{|c|c|c|c|c|c|}
\hline Compound & Therapeutic/structure & $\begin{array}{l}\text { Biological targets/mechanism of } \\
\text { action }\end{array}$ & Evaluated & $\begin{array}{l}\text { Clinical } \\
\text { trials }\end{array}$ & Ref. \\
\hline 12 & Cilengitide & $\begin{array}{l}\text { Promote av integrin inhibition. } \\
\text { Promote GSCs autophagy, cytotoxicity, } \\
\text { and cell death } \\
\text { Promote radiosensitivity. }\end{array}$ & $\begin{array}{l}\text { In vitro } \\
\text { and } \\
\text { in vivo }\end{array}$ & Yes & $\begin{array}{l}{[138]} \\
\text { PubChem } \\
\text { CID: } \\
176873\end{array}$ \\
\hline 13 & AZD2014 (Vistusertib) & $\begin{array}{l}\text { Promote } \mathrm{mTORC} 1 / 2 \text { inhibition. } \\
\text { Promote radiosensitivity. } \\
\text { Promote DNA double-strand break re- } \\
\text { pair inhibition. }\end{array}$ & $\begin{array}{l}\text { In vitro } \\
\text { and } \\
\text { in vivo }\end{array}$ & Yes & $\begin{array}{l}{[133,139-} \\
141] \\
\text { PubChem } \\
\text { CID: } \\
25262792\end{array}$ \\
\hline 14 & Eckol & $\begin{array}{l}\text { Promote radiosensitivity and TMZ } \\
\text { sensitivity. } \\
\text { Reduce neurosphere formation and } \\
\text { stem cell markers } \\
\text { Target PI3-kinase-Akt and Ras-Raf-1-Erk } \\
\text { signaling pathways. }\end{array}$ & $\begin{array}{l}\text { In vitro } \\
\text { and } \\
\text { in vivo }\end{array}$ & No & $\begin{array}{l}{[107]} \\
\text { PubChem } \\
\text { CID: } \\
145937\end{array}$ \\
\hline 15 & Nordy & $\begin{array}{l}\text { Promote GSC differentiation. } \\
\text { Reduce proliferation, stem cell } \\
\text { markers, and self-renewal } \\
\text { Target ALOX5 }\end{array}$ & $\begin{array}{l}\text { In vitro } \\
\text { and } \\
\text { in vivo }\end{array}$ & No & $\begin{array}{l}\text { [108] } \\
\text { PubChem } \\
\text { CID: } \\
319062914\end{array}$ \\
\hline 16 & $\begin{array}{c}\text { Resveratrol } \\
\mathrm{HO}\end{array}$ & $\begin{array}{l}\text { Promote radiosensitivity and } \\
\text { differentiation of GSCs. } \\
\text { HIF inhibitor. } \\
\text { Induce apoptosis of CD } 133^{+} \text {cells. } \\
\text { Target STAT3 pathway }\end{array}$ & $\begin{array}{l}\text { In vitro } \\
\text { and } \\
\text { in vivo }\end{array}$ & No & $\begin{array}{l}{[106,109]} \\
\text { PubChem } \\
\text { CID: } \\
445154\end{array}$ \\
\hline 17 & STX-0119 & $\begin{array}{l}\text { Promote inhibition of GSCs } \\
\text { proliferation. } \\
\text { Reduce stem cell markers. } \\
\text { STAT3 inhibitor. }\end{array}$ & $\begin{array}{l}\text { In vitro } \\
\text { and } \\
\text { in vivo }\end{array}$ & Yes & $\begin{array}{l}{[142]} \\
\text { PubChem } \\
\text { CID: } \\
4253236\end{array}$ \\
\hline
\end{tabular}


Table 1 Summary of current therapeutic strategies for some natural products and their chemical derivatives in GSCs. The structure, biological targets, analysis methods, clinical phase andchanism of 38 natural compounds/or derivatives are described (Continued)

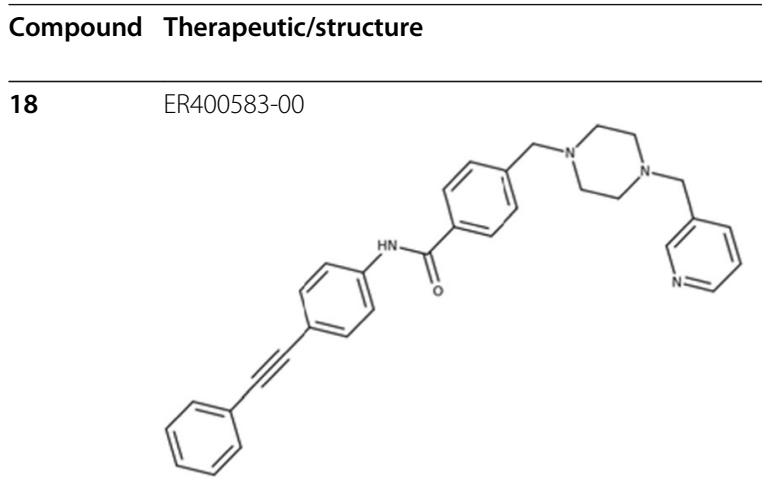

\begin{tabular}{llll}
$\begin{array}{l}\text { Biological targets/mechanism of } \\
\text { action }\end{array}$ & Evaluated & $\begin{array}{l}\text { Clinical } \\
\text { trials }\end{array}$ & Ref. \\
\hline HIF inhibitors & In vitro & No & {$[57,106$,} \\
Reduce neurosphere formation and & and & $111,143-$ \\
stem cell markers & in vivo & $148]$ \\
Inhibit VEGF signaling & & Not \\
Promote microenvironment & & available \\
modulation. & & on \\
Reduce HIF-1 expression. & & PubChem
\end{tabular}

19<smiles>N#CC(Cc1cccc(Br)n1)C(=O)N[C@H](c1ccccc1)C1CC1</smiles>

20

All-trans-retinoic acid (Vitamin A acid)<smiles>CC1=C(/C=C/C(C)=C/C=C/C(C)=C/C(=O)O)C(C)(C)CCC1</smiles>

21

Tanshinone IIA

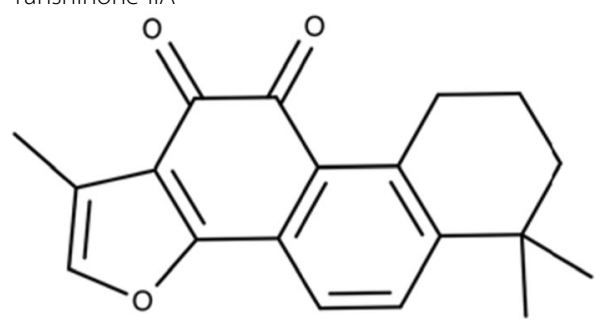

22

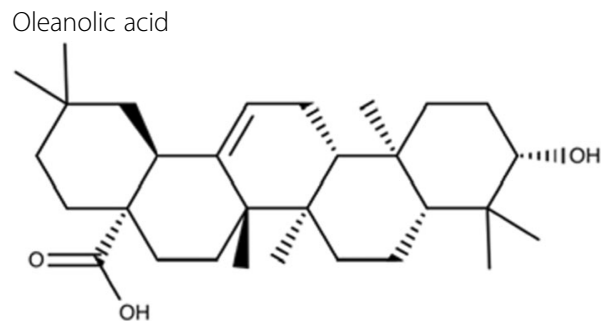

23<smiles>C[C@H](NC(=O)/C(C#N)=C/c1cccc(Br)n1)c1ccccc1</smiles>

Analog of natural product caffeic acid benzyl ester

Reduce proliferation and stem cell markers

Induce apoptosis

Promote G1 arrest decrease of cyclin

D1 and p21(Cip1/Waf-1) increase

Inhibit JAK2/STAT3

Promote differentiation

Reduce proliferation and nestin stem

cell markers

Promote apoptosis

Target ERK1/2 signaling

In vitro

and

in vivo

and

in vivo

No

[112]

Not

available

on

PubChem
Promote suppression of GSC

proliferation.

Reduce stem cell markers.

Promotes the increase of GSCs

differentiation markers.

Induce GSCs apoptosis.

Reduce the IL6/STAT3 signaling

pathway.
Promote suppression of JAK-STAT3 ac- In vitro No [156] tivation in M2 polarization of tumorassociated macrophages.
PubChem

CID:

10494
Promote STAT3 inhibition Decrease the surviving fraction of GSC
In vitro

and

in vivo
$[157,158]$

Not

available

on

PubChem 
Table 1 Summary of current therapeutic strategies for some natural products and their chemical derivatives in GSCs. The structure, biological targets, analysis methods, clinical phase andchanism of 38 natural compounds/or derivatives are described (Continued)

\begin{tabular}{|c|c|}
\hline Compound & Therapeutic/structure \\
\hline 24 & $\begin{array}{l}\text { Bevacizumab } \\
\text { >Bevacizumab light chain } \\
\text { DIQMTQSPSSLSASVGDRVTITCSASQDISNYLNWYQQKPGKAP } \\
\text { KVLIYFTSSLHSGVPSRFSGSGSGTDFTLTISSLQPEDFATYYCQQYS } \\
\text { TVPWTFGQGTKVEIKRTVAAPSVFIFPPSDEQLKSGTASWCLLNN } \\
\text { FYPREAKVQWKVDNALQSGNSQESVTEQDSKDSTYSLSSTLT } \\
\text { LSKADYEKHKVYACEVTHQGLSSPVTKSFNRGEC } \\
\text { >BeVacizumab heavy chain } \\
\text { EVQLVESGGGLVQPGGSLRLSCAASGYTFTNYGMNWVRQAPG } \\
\text { KGLEWVGWINTYTGEPTYAADFKRRFTFSLDTSKSTAYLQMNSL } \\
\text { RAEDTAVYYAKYPHYYGSSHWYFDWWGGGLVIVSSASTKGPS } \\
\text { VFPLAPSSKSTSGGTAALGCLVKDYFPEPVTVSWNSGALTSGVH } \\
\text { TFPAVLQSSGLYSLSSWTVPSSLGTQTYICNVNHKPSNTKVDKK } \\
\text { VEPKSCDKTHTCPPCPAPELLGGSVFLFPPKPKDTLMISRTPEVT } \\
\text { CWVDVSHEDPEVKFNWYVGVEVHNAKTKPREEQYNSTYRWS } \\
\text { VLTVLHQDWLNGKEYKCKVSNKALPAPIEKTISKAKGQPREPQVYT } \\
\text { LPPSREEMTKNQVSLTCLVKGFYPSDIAVEWESNGQPENNYKTTPP } \\
\text { VLDSDGSFFLYSKLTVDKSRWQQGNVFSCSVMHEALHNHYTQKS } \\
\text { LSLSPGK }\end{array}$ \\
\hline
\end{tabular}

25 Cediranib (AZD2171)<smiles>COc1cc2c(Oc3ccc4[nH]c(C)cc4c3C)ncnc2cc1OCCCN1CCCC1</smiles>

26

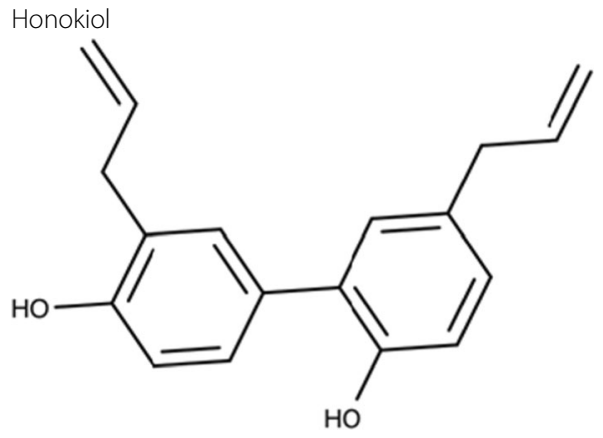

27<smiles>COc1ccc([C@@H](C)[C@@H](C)Oc2ccc([C@@H]3O[C@H](c4ccc(O[C@H](C)[C@H](C)c5ccc6c(c5)OCO6)c(OC)c4)[C@H](C)[C@H]3C)cc2OC)cc1OC</smiles>

28<smiles>COc1cc(/C=C/C(=O)CC(=O)/C=C/c2ccc(O)c(OC)c2)ccc1O</smiles>

SU5416 (Semaxinib)<smiles>Cc1cc(C)c(/C=C2\C(=O)Nc3ccccc32)[nH]1</smiles>

Biological targets/mechanism of action

Promote disruption of vascular niche and reduce tumor proliferation.

Promote radiosensitivity.

Reduce proliferation and block GSC

ability to induce endothelial cell

migration.

VEGF inhibitor

Promote disruption of the vascular niche and reduce tumor proliferation. Promote radiosensitivity. Reduce proliferation and block GSC ability to induce endothelial cell migration.

VEGF inhibitor

Promote PI3K/mTOR signaling inhibition.

Promote proliferation inhibition of side positive populations. Promote TMZ-resistant cell sensitivity. Promote DNA double-strand break repair inhibition.

Target hypoxia-inducible factor-1.

In vitro

No

[111]

PubChem

CID:

10439828

Induce GSCs apoptosis.

Target hypoxia-inducible factor-1.

In vitro

and

No

$[145,148$

in vivo

PubChem

CID:

969516

Reduce neurosphere formation and stem cell markers

Reduce HIF-1 expression

Inhibit VEGF signaling

Target PI3K/AKT/p70S6K1 signaling pathway
113,124

163]

DrugBank:

B00112

[164-166]

CID:

9933475

CID:

72303

$\begin{array}{lll}\text { In vitro } & \text { No } & {[147]} \\ \text { and } & & \text { PubChem } \\ \text { in vivo } & & \text { CID: } \\ & & 5329098\end{array}$

5329098 
Table 1 Summary of current therapeutic strategies for some natural products and their chemical derivatives in GSCs. The structure, biological targets, analysis methods, clinical phase andchanism of 38 natural compounds/or derivatives are described (Continued)

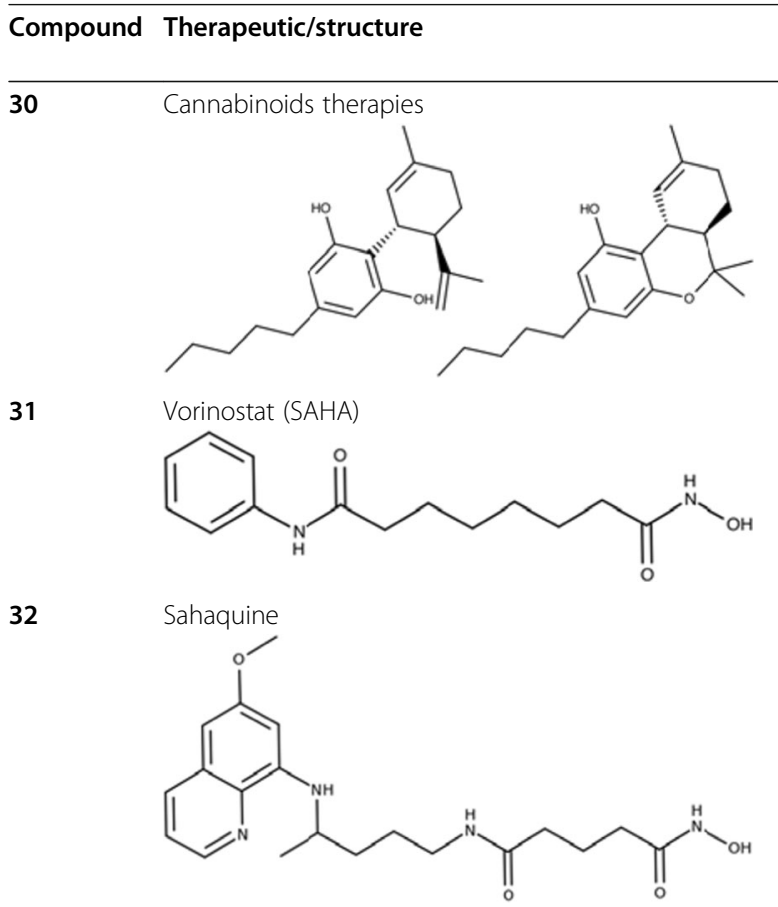

33<smiles>COc1cc(Nc2ncc3c(n2)-c2ccc(Cl)cc2C(c2c(F)cccc2OC)=NC3)ccc1C(=O)O</smiles>

34<smiles>Cc1cc(Nc2cc(N3CCN(C)CC3)nc(Sc3ccc(NC(=O)C4CC4)cc3)n2)n[nH]1</smiles>

35<smiles>CN(C)C(=N)N=C(N)N</smiles>

36

Telomestatin
Biological targets/mechanism of action

Promote differentiation.

Inhibit gliomagenesis.

Target cannabinoid type 1 (CB1) and

type 2 (CB2) receptors.

Evaluated Clinical Ref.

trials

$\begin{array}{lll}\text { In vitro } & \text { No } & {[157]} \\ \text { and } & & \text { PubChem } \\ \text { in vivo } & & \text { CID: }\end{array}$

9852188

Promote GSC differentiation.

Promote G1/S arrest of GSCs.

Inhibit histone deacetylases (HDACs).

$\begin{array}{lll}\text { In vitro } & \text { Yes } & {[150,164,} \\ \text { and } & & 165,171] \\ \text { in vivo } & & \text { PubChem } \\ & \text { CID: } \\ & 5311 \\ & \\ \text { In vitro } \quad \text { No } & \begin{array}{l}{[138]} \\ \\ \end{array} \\ & \text { Not } \\ & \text { available } \\ & \text { on } \\ & \text { PubChem }\end{array}$

Promote HDAC inhibition

Reduce GSC viability

Reduce invasiveness

PubChem

Pan-AURK inhibitor

Induce apoptosis

Reduce tumor growth

$\begin{array}{lll}\text { In vitro } & \text { No } & {[172]} \\ \text { and } & & \text { PubChem } \\ \text { in vivo } & \text { CID } \\ & & 5494449\end{array}$

Promote GSC colony formation inhibition.

Promote radiosensitivity and TMZ sensitivity.

Aurora-A kinase inhibitor.

$\begin{array}{lll}\text { In vitro } & \text { No } & \text { [173-175] } \\ \text { and } & & \text { PubChem } \\ \text { in vivo } & & \text { CID: } \\ & & 24771867\end{array}$

Promote inhibition of GSC selfrenewal.

Reduce GSC viability.

Promote inhibition of CD133+

proliferation.

$\begin{array}{lll}\text { In vitro } & \text { No } & \text { [176-181] } \\ \text { and } & \text { PubChem } \\ \text { in vivo } & \text { CID: } \\ & 4091\end{array}$

Polyketide component

Induce apoptosis and impair the migration potential of GSCs.

Promote telomeric and nontelomeric DNA damage in GSCs.

$\begin{array}{lll}\text { In vitro } & \text { No } & {[182]} \\ \text { and } & & \text { PubChem } \\ \text { in vivo } & \text { CID: } \\ & & 443590\end{array}$


Table 1 Summary of current therapeutic strategies for some natural products and their chemical derivatives in GSCs. The structure, biological targets, analysis methods, clinical phase andchanism of 38 natural compounds/or derivatives are described (Continued)

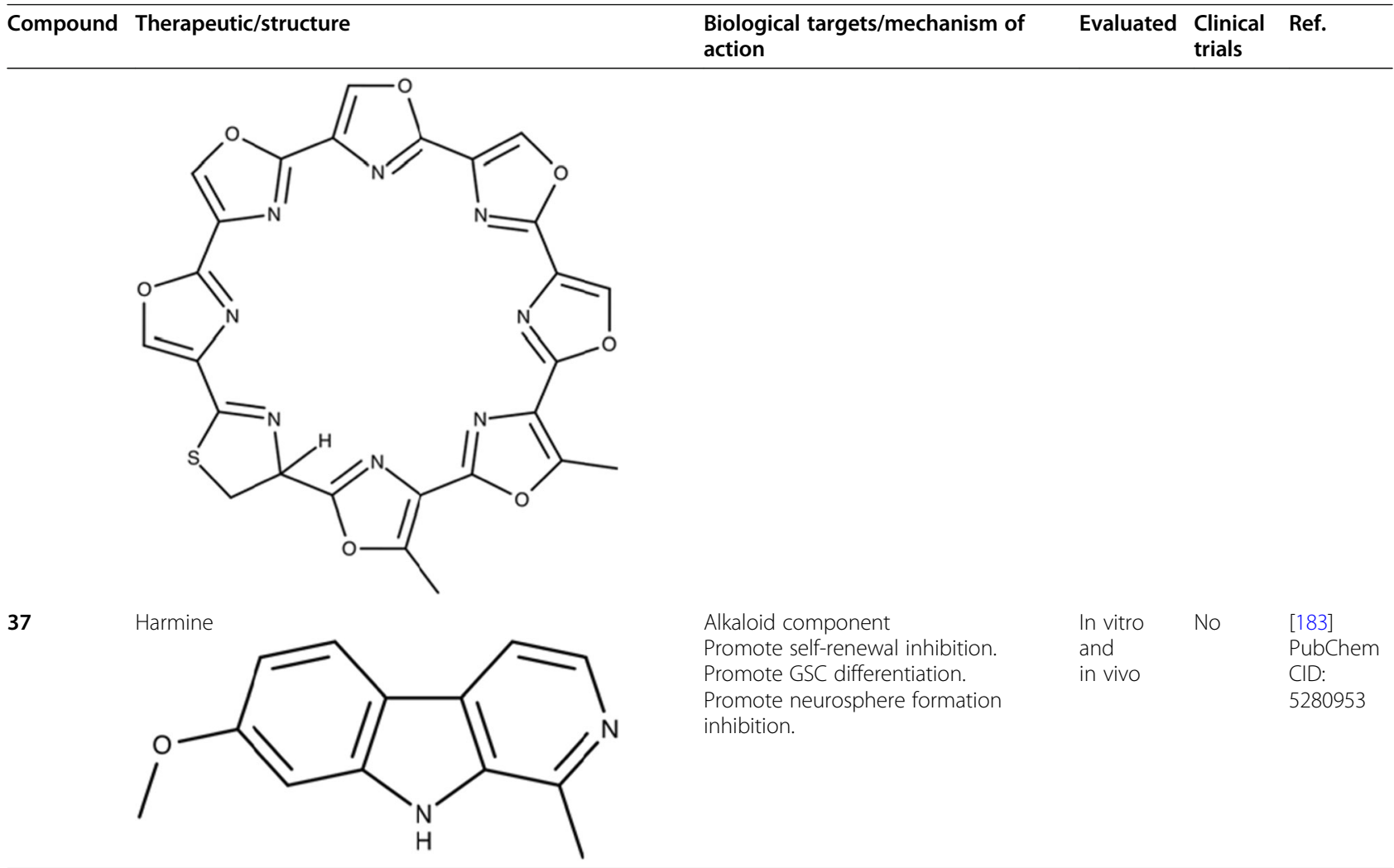

* For chemical structures, SDF files were retrieved from PubChem [184], and 2D structures were built on MarvinSketch (MarvinSketch 19.27.0, 2019, ChemAxon (http://www.chemaxon.com)

Given the requirement for hedgehog $(\mathrm{Hh})$ signaling in GSCs, a recent study investigated cyclopamine (11-deoxojervine) (1) and guggulsterone (2) [114, 185]. Cyclopamine can specifically inhibit the Hh pathway [117] as well as the side and aldefluor-positive populations, resulting in cultures unable to form colonies in preclinical studies and GSCs sensitized to radiation [118, 185]. Another important protein able to target different pathways (Hedgehog, Notch, and $\beta$-catenin) is casein kinase 2 (CK2) [119]. In GBM, CK2 expression and activity lead to tumor suppressor inhibition and oncogene activation contributing to gliomagenesis [119]. Moreover, CK2 inhibition promotes O6-methylguanine-DNA-methyltransferase downregulation and sensitizes glioma cells to TMZ [121]. CX-4945 (3) is potent, selective, and highly bioavailable compared to other CK2 inhibitors [121]. This novel molecule and its analogs target several GSC factors and markers and exhibit promising results in preclinical studies of several types of tumors, in vivo models and human clinical trials $[121,186]$.

Regarding the cell cycle and DNA damage repair [122, 123], there are several $\mathrm{CHK} 1$ and $\mathrm{CHK} 2$ inhibitors; CHK1 inhibitors in clinical development include $\mathrm{SCH}$ 900776 (NCT00779584) (4) and SAR-020106 (5) [124,
125]. AZD7762 (NCT00413686) (6) and debromohymenialdisine (DBH) (7) are novel potent checkpoint kinase inhibitors that inhibit both CHK1 and CHK2. AZD7762 was shown to potentiate chemotherapy response in several different settings and resulted in the abrogation of DNA damage-induced cell cycle arrest in vitro and in vivo in combination with DNA-damaging agents [126, 127]. The use of $\mathrm{DBH}$ and radiation treatment is synergistic: together they are able to abrogate the radioresistance of $\mathrm{CD}_{133^{+}}$cells, suggesting new options for combination radiotherapy $[31,128]$.

EGFR is a crucial receptor in the protocols described for growing GSCs, making clear that this pathway is necessary for GSC survival $[129,130]$. Thus, it would be rational to use EGFR inhibitors to promote the inhibition of GSC proliferation and self-renewal and induce cell death [129, 137]. First-generation EGFR inhibitors such as erlotinib (8) and gefitinib (9) have been used in the clinical treatment of glioma patients, although less than $20 \%$ of patients presented a response to these treatments. However, EGFR inhibition has been observed to enhance the chemo- and radiosensitivity of human glioma CSCs [136, 137]. It is believed that the low response to these inhibitors is associated with loss of the tumor 


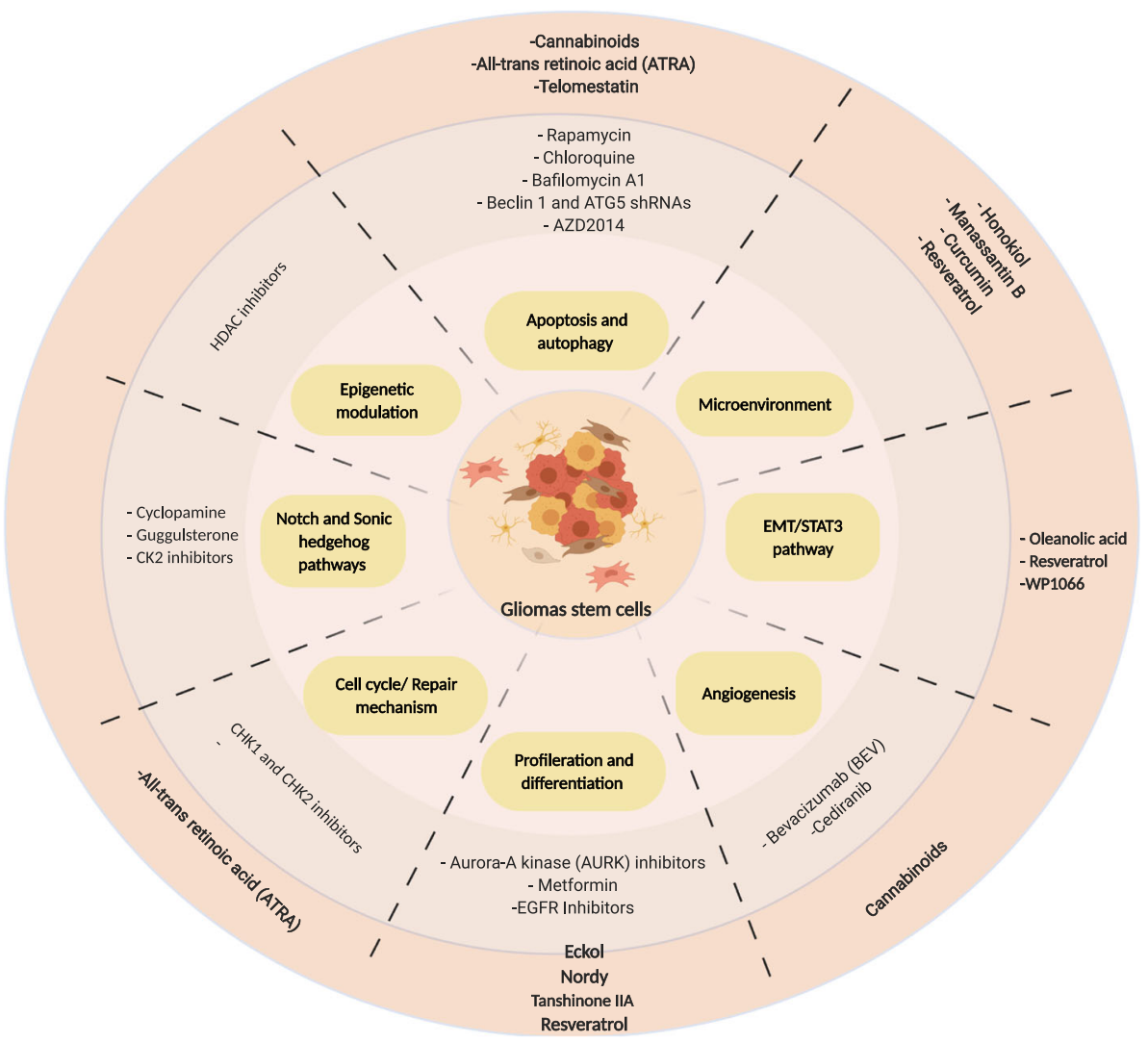

Fig. 3 A schematic representation of the molecular signaling hallmarks of glial stem cell (CSC) and the effect of natural compounds and synthetic drugs on these molecular targets. In the dark red circle are represented natural compounds that target each hallmark. In light red are represented chemicals/synthetic drugs that targeted each hallmark in GSC. See text for details (created with Biorender.com)

suppressor PTEN, which is usually deleted or mutated in gliomas and plays a critical role in maintaining neural precursor cells via activation of the mTOR pathway [133, 139]. Clinical results with rapamycin (10) have been described in patients with high-grade GBM [140, 141] and have demonstrated that treatment with rapamycin or combination with EGFR inhibitors may provide an alternative treatment for TMZ-resistant gliomas, regardless of EGFR status [134, 142].

Related to autophagy, the cell death and survival response can be influenced to favor cell death through several therapies that inhibit autophagy processes [155]. Chloroquine (CQ) (11) is an applicable autophagy inhibitor known to trigger apoptosis in conventional autophagic tumor cells and to improve mid-term survival in glioma when administered in addition to conventional therapy $[187,188]$. Regarding GSCs, triple combinations of $\gamma \mathrm{IR}$, low-dose CQ, and PI3K/Akt pathway inhibitors or high-dose CQ alone induced strong cytotoxic effects in radioresistant GSCs [187]. Moreover, inhibitors such as bafilomycin A1 or beclin 1 and ATG5 shRNAs also sensitize GSCs to radiation and reduce their viability and capacity to form neurospheres [134, 189]. Likewise, radiation and the inhibition of $\alpha \mathrm{v}$ integrin by cilengitide (12), which is currently in clinical evaluation, induce autophagy in GSCs, increasing cytotoxicity and reducing cell survival [190].

In addition, the association of mTOR inhibitors and radiation led authors to evaluate the effects of AZD2014 (13) [156], a competitive dual mTORC1/2 inhibitor, unlike rapamycin, an allosteric inhibitor, on the radiosensitivity of GSCs in in vitro and in vivo studies [191]. Beyond these properties, AZD2014 also penetrates the blood-brain barrier and has been reported in a Phase I clinical trial as a single agent $[156,159,160]$. The authors showed that AZD2014-mediated radiosensitization in GSCs promoted the inhibition of DSB repair as evaluated by a clonogenic assay according to $\gamma \mathrm{H} 2 \mathrm{AX}$ foci. Additionally, in GSC-initiated orthotopic xenografts, AZD2014, when combined with radiation, significantly prolonged mouse survival even when administered for only 3 days. These data indicate that AZD2014 may be a radiosensitizer applicable to GBM therapy [192].

Moreover, other molecules can decrease the stemness properties of GSCs, including eckol (14) [107], Nordy (15) [108], resveratrol (16) [109], STX-0119 (17) [161], 
ER400583-00 (18) [110], WP1193 (19) [111], angiogenesis inhibitors [143], all-trans-retinoic acid (20) [144], and Tanshinone IIA (21) [145]. Some of these molecules are linked to targets the microenvironment and thus indirectly modulate the stemness properties of cancer cells. However, these drugs cannot be used for a specific tumor type because the role of each niche in different tumor types and how they differ from one another is not yet known. This class includes molecules that primarily target angiogenesis and hypoxia $[107,108,110,111,145]$.

Eckol (14), a phlorotannin compound from Ecklonia species, has been shown to attenuate in vitro anchorageindependent growth on soft agar and reduce sphere formation and GSC markers. Moreover, the $\mathrm{CD} 133^{+}$subpopulation and self-renewal-related proteins were decreased in response. The authors suggested that eckol activity could target PI3K/Akt and MAPK signaling pathways. Importantly, eckol treatment also decreases the resistance of GSCs to IR and TMZ and tumor formation in xenograft mice $[107,146]$.

The synthetic dl-nordihydroguaiaretic acid compound Nordy (15) was also shown to inhibit self-renewal properties, induce GSC differentiation, and decrease the GSC pool in vitro and in vivo. Alox-5 is a Nordy target that promotes the invasion and proliferation inhibition of GSCs. Moreover, Nordy promotes GFAP upregulation, angiogenesis inhibition, and stemness marker downregulation [108, 147].

Regarding pluripotency, signal transducer and activator of transcription 3 (STAT3), which is associated with the cell cycle and survival, regulation, immune response, and differentiation, has been described as a critical initiator and regulator of tumorigenic transformation in GBM and implicated among GSC maintenance factors. STAT3 has been related to oncogenic or tumorsuppressive roles in GBM depending on the tumor genotype $[111,167]$. These novel therapies may be the basis for the next generation of GBM treatment. STAT3 signaling includes small molecules such as oleanolic acid (22) [168], STX-0119 (13) [161], and WP1066 (23) [157]. Resveratrol (16) (RV), a polyphenol in grapes, is known to be a potential noncytotoxic tumor-preventive drug targeting STAT3 signaling. In glioma, RV can induce apoptosis, enhance radiosensitivity in the $\mathrm{CD}_{133^{+}}$cell population, and decrease tumorigenicity in xenotransplant experiments. Furthermore, RV was able to inhibit cell proliferation and decrease cell motility by modulating the Wnt signaling pathway and EMT activators $[109,193]$.

Another novel molecule recently investigated is WP1066 (23), an analog of the natural product caffeic acid benzyl ester and a potent STAT3 pathway inhibitor. In glioma, this potent small-molecule inhibitor showed promise as a therapeutic agent by targeting GSCs and will be investigated in a clinical trial for patients with recurrent malignant glioma and brain metastasis from melanoma (recruiting, ClinicalTrials.gov). In addition, WP1066 can cross the blood-brain barrier and is orally bioavailable $[157,194]$.

Antiangiogenic agents that disrupt GBM-initiating cell maintenance have been widely investigated, but so far, only modest results have been obtained. Moreover, some reports have indicated that glioma develops resistance to the employed antiangiogenic treatments $[195,196]$. To date, in highly vascular tumors such as gliomas [149, 197], angiogenesis inhibition has improved progressionfree survival, although no cure has been achieved. Clinical trials using bevacizumab (BEV) (24) and cediranib (AZD2171) (25) (Phase I) alone or in combination have demonstrated efficacy in GBM patients $[164,165]$. In in vivo experimental studies with mice, BEV treatment decreased GSCs and the growth rate of GBMs [2].

Regarding clinical trials, BEV (24) has been combined with irinotecan (Phase II) and pazopanib, also an oral multitarget angiogenesis inhibitor (GW786034) (Phases I and II) $[143,164,165]$. A study also demonstrated that $\mathrm{BEV}$ or interferon-beta could enhance radiosensitivity in orthotopic GBM [171]. However, recent studies suggest that inhibition of angiogenesis is even a driving force for tumor conversion to a higher malignancy state, inducing a phenotypic change from single-cell infiltration to migration of cell clusters along normal blood vessels, which is reflected in higher invasion, enhanced metastatic activity and dissemination $[150,196]$.

Moreover, antiangiogenic therapy changes tumor vasculature, leading to hypoxia [196]. The hypoxia phenotype has been demonstrated as a marker of antiangiogenic therapy resistance by $H I F-1 \alpha$ and stromal-cell derived factor- $1 \alpha$ $(S D F-1 \alpha)$ upregulation leading to the recruitment of various pro-angiogenic bone marrow-derived cells [196]. For hypoxia modulation, compelling data demonstrate that the downregulation of HIF2- $\alpha$ can increase stem cell/pluripotency markers, neurosphere formation, and the VEGF pathway $[57,151]$. Thus, several molecules that inhibit or indirectly modulate the expression of HIF-1 have been investigated, although they showed little efficacy either alone or in combination with standard antitumor agents [152]. For instance, honokiol (26), manassantin (27) B from Saururus cernuus and Saururus chinensis, curcumin from Curcuma spp. (28), resveratrol (16), SU5416 (29), and ER400583-00 (18) are inhibitors that have been developed [106, 109, 110, 153, 164, 198, 199].

Honokiol (26) is one of the biphenolic bioactive compounds isolated from Magnolia officinalis, possessing multifunctional activities in addition to crossing the blood-brain barrier [173, 174]. Honokiol specifically inhibits PI3K/mTOR signaling activation in gliomas [173, 175], promotes the elimination of GSCs, and reverses TMZ resistance using GBM8401 SP cells, which appear to have higher expression of $M G M T$ and to be more 
resistant to TMZ. This inhibition is accompanied by a greater induction of apoptosis and reduced expression levels of EGFR, CD133, and Nestin, suggesting that honokiol might have clinical benefits for GBM patients, mainly those who are refractory to TMZ treatment $[75,173,176]$.

Furthermore, several agents, such as cannabinoids (30), are known to exert antitumor action on GBM by apoptosis induction and tumor angiogenesis inhibition and have been recently evaluated in GSC differentiation control. The study provides further support for the hypothesis that cannabinoid changes reduce glioma initiation (neurosphere formation and cell proliferation) in vivo. These effects were greater in combination with TMZ and correlated with an increase in cell differentiation $[177,200]$. Another strategy to reduce the tumorigenic potential of GSCs and promote differentiation is to induce bone morphogenic proteins (BMP) signaling $[165,178]$. The potential of BMP induction of astrocyte differentiation from normal neural precursors has been reported in vitro and in vivo $[149,205]$. Most importantly, BMP4 has been shown to trigger a significant decrease in GSCs $[165,178,179]$. Even with BMP signaling, it was identified that BMP2 heightens sensitivity to TMZ in GSCs in which MGMT expression was described as directly downregulated by HIF-1 $\alpha$ at the transcriptional level [180, 201].

The epigenetic modulation of histone acetylation by histone deacetylase (HDAC) activity has been associated with several cancer types [182, 202]. The HDAC inhibitor, vorinostat (suberoylanilide hydroxamic acid, SAHA) (31), and sahaquine (32) are currently in Phase I clinical trials $[138,183,203]$ in GBM. In vitro, SAHA has shown antiproliferative effects by blocking G1/S phase progression, increasing the levels of apoptosis-related genes and inducing the expression of cleaved PARP and $\mathrm{p}-\gamma \mathrm{H} 2 \mathrm{AX}$ in GSCs [204]. Sahaquine inhibits HDAC6, leading to a reduction in the viability and invasiveness of glioblastoma tumors and brain tumor stem cells [138]. Most importantly, HDAC inhibitor treatment under culture proliferation conditions suggests the induction of differentiated cell states in adult mouse neural stem cells [205].

In addition, all-trans-retinoic acid (ATRA) (20), a differentiating agent used in clinical practice, is a natural compound derivative of retinoic acid, also known as vitamin A [202, 206]. Some findings reported its capacity for differentiating stem cells as well as normal neural progenitor cells and downregulating the expression of the stem cell marker nestin [207, 208]. An additional study revealed that a combination of ATRA and paclitaxel was able to synergistically reduce GBM tumor growth in both in vivo and in vitro models [209]. GSCs differentiated into glial and neuronal lineages even at low concentrations of ATRA. Moreover, ATRA decreased proliferation and self-renewal of neurospheres and promoted apoptosis at high concentrations, targeted ERK1/2 signaling, induced cell cycle arrest at the G1/G0 to $\mathrm{S}$ transition, decreased cyclin D1 expression, and increased p27 expression [206, 210].

Another agent with antiproliferative and prodifferentiation effects in GSCs is aurora-A kinase (AURK), a crucial serine-threonine kinase $[211,212]$ observed to be variably overexpressed in gliomas [211, 213]. AURK is also a vital kinase that governs self-renewal capacity in GBM tumorsphere cultures [172]. These authors used a pan-AURK inhibitor, VX680 (33), followed by radiation, in cell culture and xenograft models, and demonstrated the induction of apoptosis and reduction of tumor growth [172]. Hong and coworkers also demonstrated that MLN8237 (alisertib) (34) [214-216], a highly selective AURK inhibitor, inhibits colony formation in GSCs and potentiates the effects of radiation and TMZ in glioblastoma monolayers and GSCs [217]. Importantly, MLN8237 is relatively non-toxic to normal human astrocytes.

Another emerging antiglioma drug is metformin (35), a drug used mainly for the therapy of type 2 diabetes and polycystic ovary syndrome [218, 219]. Metformin treatment in vitro was able to block cell cycle progression (G0/G1 phase), although cell death was not observed in GBMs [220]. In a recent report, metformin selectively and remarkably affects GSC viability in vitro [221]. The authors showed that $A K T$ and the transcription factor forkhead box $\mathrm{O} 3$ (FOXO3) are involved in the molecular mechanism of metformin activity in GSCs [222, 223]. The effects of metformin were also validated in preclinical glioma orthotopic animal models, in which metformin administration resulted in a decrease of the self-renewing properties and tumor-initiating subpopulation [162, 224]. Clinical trials on the use of metformin alone and cancer treatment (including glioma) and prevention are ongoing $[219,224]$.

Maruccia and coworkers reviewed exciting results obtained with forty-nine different natural products, including flavonoids, alkaloids, polyketides, and acid derivatives [225]. One terpene or terpenoid compound class that has been reported in GSCs is the retinoic acids (all-trans), which are potent differentiating agents $[144,226]$. The retinoic acids induce the in vitro differentiation of GSCs and impair the secretion of angiogenic cytokines and GSC motility, promoting synergistic therapy. The antitumor mechanism is associated with the downregulation of Wnt/-catenin signaling [166]. Well-characterized polyketides are telomestatin (36) and derivatives from Streptomyces anulatus, able to induce apoptosis and impair migration potential of GSCs in vitro and in vivo and to moderately change non-GSCs and normal neural precursors. Moreover, these macrocyclic compounds also 
promoted telomeric and nontelomeric DNA damage in GSCs [227, 228]. Two different alkaloids have been reported to be active against GSCs: cyclopamine (1) from Veratrum californicum and harmine (37) from Peganum harmala $[55,115,170]$. It was demonstrated that harmine inhibits self-renewal and induces GSC differentiation. In particular, harmine inhibits neurosphere formation of human primary glioblastoma GSCs and AKT phosphorylation [229].

\section{Conclusion}

The development of effective therapy for GBM remains a significant challenge in molecular oncology due to several questions mentioned above. Here, we have discussed several bioactive products that have been reported to modulate GSCs and shown to be essential for therapeutic applications. Although the detailed underlying mechanisms are unknown, bioactive products hold promise for the development of new drugs to treat glioma. Advances in understanding the pathomechanisms of glioma and the identification of GSC properties and therapeutic targets in the GSC subpopulation offer new directions for the development of novel therapies, either isolated or in combination, using personalized targeting for primary brain tumors, which is further emphasized in strategies for basic and translational research with natural compounds.

Papers of special note have been highlighted as either of interest $(76,93)$ or of considerable interest $(15,39,78$, 112) to readers

\begin{abstract}
Abbreviations
ATM: Ataxia-telangiectasia mutated; ATRA: All-trans retinoic acid; ATR: Ataxiatelangiectasia and Rad3 related; ATRX: Alpha-thalassemia/mental retardation syndrome X-linked; BMP: Bone morphogenic proteins; Bev: Bevacizumab; CSC: Cancer stem cell; CXCR4: C-X-C motif chemokine receptor 4; CDKN2A: Cyclin-dependent kinase inhibitor 2A; CD184: CXCR4 chemokine receptor; CQ: Chloroquine; DBH: Debromohymenialdisine; DSBs: DNA double-strand breaks; FOXO3: Forkhead box O3; GBM: Glioblastoma; GFAP: Glial fibrillary acidic protein; GSC: Glial stem cell; EMT: Epithelialmesenchymal transition; HDACs: Histone deacetylase; HIF: Hypoxia-inducible factor; IDH-1: Isocitrate dehydrogenase 1; TP53: Tumor protein P53; IR: Ionizing radiation; EFGR: Epidermal growth factor receptor; LC3: Microtubule-associated protein 1A/1B-light chain 3; MGMT: O6methylguanine-DNA-methyltransferase; MDR1: Expression of multidrug resistance 1; mTOR: Mammalian targets of rapamycin; PTEN: Phosphatase and tensin homolog; TERT: Telomerase reverse transcriptase; Rv: Resveratrol; STAT3: Activator of transcription 3; SDF1 a: Stromal-cell derived factor-1a; TMZ: Temozolomide; VEGF: Vascular endothelial growth factor
\end{abstract}

\section{Acknowledgements}

The authors gratefully acknowledge Tatiana Honda Morais for discussion of the manuscript and Caio Fernando Oliveira for the excellent assistance in using the Biorender platform.

\section{Authors' contributions}

ACC, VAOS, and RMR contributed to the conceptualization. ALVA, INFG, ACC, MNR, LSdS, AFE, and VAOS contributed to the investigation and wrote the original draft of the manuscript. All authors read and approved the final manuscript.

\section{Funding}

This study was supported by FAPESP (Fundação de Amparo à Pesquisa do Estado de São Paulo) (grants 2019/05142-4 - A.L.V.A; 2017/22305-9- I.N.F.G), Public Ministry of Labor Campinas (Research, Prevention and Education of Occupational Cancer) - L.S.S, CAPES and Barretos Cancer Hospital, all from Brazil.

\section{Availability of data and materials}

Not applicable.

\section{Declarations}

Ethics approval and consent to participate

Not applicable.

\section{Consent for publication}

Not applicable.

\section{Competing interests}

The authors declare that they have no competing interests.

\section{Author details}

${ }^{1}$ Molecular Oncology Research Center, Barretos Cancer Hospital, Rua Antenor Duarte Villela, 1331, CEP 14784 400, Barretos, São Paulo, Brazil. ² Life and Health Sciences Research Institute (ICVS), School of Medicine, University of Minho, 4710-057 Braga, Portugal. ${ }^{3}$ ICVS/3B's PT Government Associate Laboratory, 4806-909 Braga, Portugal.

Received: 18 August 2020 Accepted: 15 February 2021

Published online: 24 March 2021

\section{References}

1. Ostrom QT, Cioffi G, Gittleman H, et al. CBTRUS Statistical Report: primary brain and other central nervous system tumors diagnosed in the United States in 2012-2016. Neuro Oncol. 2019;21(Supplement_5):v1-v100.

2. Louis DN, Perry A, Reifenberger G, et al. The 2016 World Health Organization classification of tumors of the central nervous system: a summary. Acta Neuropathol. 2016;131(6):803-20.

3. Patterson JD, Wongsurawat T, Rodriguez A. A glioblastoma genomics primer for clinicians. Med Res Arch. 2020;8(2):1-13.

4. Hanif F, Muzaffar K, Perveen K, et al. Glioblastoma Multiforme: a review of its epidemiology and pathogenesis through clinical presentation and treatment. Asian Pac J Cancer Prev. 2017;18(1):3-9.

5. $\mathrm{Xu} \mathrm{H}$, Zong $\mathrm{H}, \mathrm{MaC}$, et al. Epidermal growth factor receptor in glioblastoma. Oncol Lett. 2017;14(1):512-6.

6. Eckel-Passow JE, Lachance DH, Molinaro AM, et al. Glioma groups based on $1 \mathrm{p} / 19 \mathrm{q}, \mathrm{IDH}$, and TERT promoter mutations in tumors. N Engl J Med. 2015; 372(26):2499-508.

7. Foote MB, Papadopoulos N, Diaz LA Jr. Genetic classification of gliomas: refining histopathology. Cancer Cell. 2015;28(1):9-11.

8. Brat DJ, Aldape K, Colman H, et al. CIMPACT-NOW update 5: recommended grading criteria and terminologies for IDH-mutant astrocytomas. Acta Neuropathol. 2020;139(3):603-8.

9. Chaurasia A, Park SH, Seo JW, et al. Immunohistochemical analysis of ATRX, IDH1 and p53 in glioblastoma and their correlations with patient survival. J Korean Med Sci. 2016;31(8):1208-14.

10. Lathia JD, Mack SC, Mulkearns-Hubert EE, et al. Cancer stem cells in glioblastoma. Genes Dev. 2015;29(12):1203-17.

11. Ostrom QT, Gittleman H, Truitt G, et al. CBTRUS Statistical Report: primary brain and other central nervous system tumors diagnosed in the United States in 2011-2015. Neuro Oncol. 2018;20(suppl_4):iv1-iv86.

12. Aparicio-Blanco J, Sanz-Arriazu L, Lorenzoni R, et al. Glioblastoma chemotherapeutic agents used in the clinical setting and in clinical trials: Nanomedicine approaches to improve their efficacy. Int J Pharm. 2020;581: 119283

13. Taylor OG, Brzozowski JS, Skelding KA. Glioblastoma Multiforme: an overview of emerging therapeutic targets. Front Oncol. 2019;9:963.

14. Lapidot T, Sirard C, Vormoor J, et al. A cell initiating human acute myeloid leukaemia after transplantation into SCID mice. Nature. 1994;367(6464):645-8. 
15. Ignatova TN, Kukekov VG, Laywell ED, et al. Human cortical glial tumors contain neural stem-like cells expressing astroglial and neuronal markers in vitro. Glia. 2002;39(3):193-206.

16. Hemmati HD, Nakano I, Lazareff JA, et al. Cancerous stem cells can arise from pediatric brain tumors. Proc Natl Acad Sci U S A. 2003;100(25):1517883.

17. Kondo T, Setoguchi T, Taga T. Persistence of a small subpopulation of cancer stem-like cells in the C6 glioma cell line. Proc Natl Acad Sci U S A. 2004;101(3):781-6.

18. Singh SK, Clarke ID, Terasaki M, et al. Identification of a cancer stem cell in human brain tumors. Cancer Res. 2003;63(18):5821-8.

19. Singh SK, Hawkins C, Clarke ID, et al. Identification of human brain tumour initiating cells. Nature. 2004;432(7015):396-401.

20. Pollard SM, Yoshikawa K, Clarke ID, et al. Glioma stem cell lines expanded in adherent culture have tumor-specific phenotypes and are suitable for chemical and genetic screens. Cell Stem Cell. 2009;4(6):568-80.

21. McCord AM, Jamal M, Williams ES, et al. CD133+ glioblastoma stem-like cells are radiosensitive with a defective DNA damage response compared with established cell lines. Clin Cancer Res. 2009;15(16):5145-53.

22. Galli R, Binda E, Orfanelli $U$, et al. Isolation and characterization of tumorigenic, stem-like neural precursors from human glioblastoma. Cancer Res. 2004;64(19):7011-21.

23. Dirks PB. Brain tumor stem cells: the cancer stem cell hypothesis writ large Mol Oncol. 2010;4(5):420-30.

24. Pallini R, Ricci-Vitiani L, Banna GL, et al. Cancer stem cell analysis and clinical outcome in patients with glioblastoma multiforme. Clin Cancer Res. 2008; 14(24):8205-12.

25. Tomita T, Akimoto J, Haraoka J, et al. Clinicopathological significance of expression of nestin, a neural stem/progenitor cell marker, in human glioma tissue. Brain Tumor Pathol. 2014;31(3):162-71.

26. Zhang M, Song T, Yang L, et al. Nestin and CD133: valuable stem cellspecific markers for determining clinical outcome of glioma patients. J Exp Clin Cancer Res. 2008;27:85

27. Bjerkvig R, Tysnes BB, Aboody KS, et al. Opinion: the origin of the cance stem cell: current controversies and new insights. Nat Rev Cancer. 2005; 5(11):899-904

28. Ehtesham M, Mapara KY, Stevenson CB, et al. CXCR4 mediates the proliferation of glioblastoma progenitor cells. Cancer Lett. 2009;274(2):30512.

29. Persano L, Rampazzo E, Basso G, et al. Glioblastoma cancer stem cells: role of the microenvironment and therapeutic targeting. Biochem Pharmacol. 2013;85(5):612-22

30. Soehngen E, Schaefer A, Koeritzer J, et al. Hypoxia upregulates aldehyde dehydrogenase isoform 1 (ALDH1) expression and induces functional stem cell characteristics in human glioblastoma cells. Brain Tumor Pathol. 2014; 31(4):247-56.

31. Bao S, Wu Q, McLendon RE, et al. Glioma stem cells promote radioresistance by preferential activation of the DNA damage response. Nature. 2006:444(7120):756-60.

32. Ma J, Yao $Y$, Wang $P$, et al. MiR-152 functions as a tumor suppressor in glioblastoma stem cells by targeting Kruppel-like factor 4. Cancer Lett. 2014; 355(1):85-95.

33. Zhang $L$, Yan $Y$, Jiang $Y$, et al. The expression of SALL4 in patients with gliomas: high level of SALL4 expression is correlated with poor outcome. J Neuro-Oncol. 2015:121(2):261-8.

34. Di Tomaso T, Mazzoleni S, Wang E, et al. Immunobiological characterization of cancer stem cells isolated from glioblastoma patients. Clin Cancer Res. 2010;16(3):800-13.

35. Jung CS, Foerch C, Schanzer A, et al. Serum GFAP is a diagnostic marker for glioblastoma multiforme. Brain. 2007;130(Pt 12):3336-41.

36. Clement $V$, Dutoit $V$, Marino D, et al. Limits of CD133 as a marker of glioma self-renewing cells. Int J Cancer. 2009;125(1):244-8.

37. Stieber D, Golebiewska A, Evers L, et al. Glioblastomas are composed of genetically divergent clones with distinct tumourigenic potential and variable stem cell-associated phenotypes. Acta Neuropathol. 2014;127(2): 203-19.

38. Bradshaw A, Wickremsekera A, Tan ST, et al. Cancer stem cell hierarchy in Glioblastoma Multiforme. Front Surg. 2016:3:21.

39. Rosenblum ML, Gerosa M, Dougherty DV, et al. Age-related chemosensitivity of stem cells from human malignant brain tumours. Lancet. 1982;1(8277):885-7.
40. Morgan MA, Lawrence TS. Molecular pathways: overcoming radiation resistance by targeting DNA damage response pathways. Clin Cancer Res. 2015;21(13):2898-904.

41. Pilie PG, Tang C, Mills GB, et al. State-of-the-art strategies for targeting the DNA damage response in cancer. Nat Rev Clin Oncol. 2019;16(2):81-104.

42. Schulz A, Meyer F, Dubrovska A, et al. Cancer stem cells and Radioresistance: DNA repair and beyond. Cancers. 2019;11(6):1-20.

43. Tamura K, Aoyagi M, Ando N, et al. Expansion of CD133-positive glioma cells in recurrent de novo glioblastomas after radiotherapy and chemotherapy. J Neurosurg. 2013;119(5):1145-55.

44. Tamura K, Aoyagi M, Wakimoto $\mathrm{H}$, et al. Accumulation of CD133-positive glioma cells after high-dose irradiation by Gamma Knife surgery plus external beam radiation. J Neurosurg. 2010;113(2):310-8.

45. Balbous A, Cortes U, Guilloteau K, et al. A radiosensitizing effect of RAD51 inhibition in glioblastoma stem-like cells. BMC Cancer. 2016;16: 604.

46. King $\mathrm{HO}$, Brend $\mathrm{T}$, Payne $\mathrm{HL}$, et al. RAD51 is a selective DNA repair target to Radiosensitize Glioma stem cells. Stem Cell Rep. 2017;8(1):125-39.

47. Ahmed SU, Carruthers R, Gilmour L, et al. Selective inhibition of parallel DNA damage response pathways optimizes radiosensitization of glioblastoma stem-like cells. Cancer Res. 2015;75(20):4416-28.

48. Carruthers R, Ahmed SU, Strathdee K, et al. Abrogation of radioresistance in glioblastoma stem-like cells by inhibition of ATM kinase. Mol Oncol. 2015; 9(1):192-203.

49. Hambardzumyan D, Gutmann DH, Kettenmann $\mathrm{H}$. The role of microglia and macrophages in glioma maintenance and progression. Nat Neurosci. 2016; 19(1):20-7.

50. Hambardzumyan D, Bergers G. Glioblastoma: defining tumor niches. Trends Cancer. 2015;1(4):252-65.

51. Mannino M, Chalmers AJ. Radioresistance of glioma stem cells: intrinsic characteristic or property of the 'microenvironment-stem cell unit'? Mol Oncol. 2011:5(4):374-86.

52. Peitzsch C, Perrin R, Hill RP, et al. Hypoxia as a biomarker for radioresistant cancer stem cells. Int J Radiat Biol. 2014;90(8):636-52.

53. Fidoamore A, Cristiano L, Antonosante A, et al. Glioblastoma stem cells microenvironment: the paracrine roles of the niche in drug and radioresistance. Stem Cells Int. 2016;2016:6809105.

54. Wang $\mathrm{P}$, Lan C, Xiong $\mathrm{S}$, et al. HIF1alpha regulates single differentiated glioma cell dedifferentiation to stem-like cell phenotypes with high tumorigenic potential under hypoxia. Oncotarget. 2017;8(17):28074-92.

55. Bar EE, Lin A, Mahairaki $\mathrm{V}$, et al. Hypoxia increases the expression of stemcell markers and promotes clonogenicity in glioblastoma neurospheres. Am J Pathol. 2010;177(3):1491-502

56. De Miguel MP, Alcaina Y, de la Maza DS, et al. Cell metabolism under microenvironmental low oxygen tension levels in stemness, proliferation and pluripotency. Curr Mol Med. 2015;15(4):343-59.

57. Li Z, Bao S, Wu Q, et al. Hypoxia-inducible factors regulate tumorigenic capacity of glioma stem cells. Cancer Cell. 2009;15(6):501-13.

58. Wang G, Wang JJ, Fu XL, et al. Advances in the targeting of HIF-1alpha and future therapeutic strategies for glioblastoma multiforme (review). Oncol Rep. 2017:37(2):657-70.

59. Christensen K, Schroder HD, Kristensen BW. CD133 identifies perivascular niches in grade II-IV astrocytomas. J Neuro-Oncol. 2008;90(2):157-70.

60. Wang R, Chadalavada K, Wilshire J, et al. Glioblastoma stem-like cells give rise to tumour endothelium. Nature. 2010:468(7325):829-33.

61. Ricci-Vitiani $L$, Pallini R, Biffoni $M$, et al. Tumour vascularization via endothelial differentiation of glioblastoma stem-like cells. Nature. 2010; 468(7325):824-8

62. Jamal M, Rath $B$ H, Tsang PS, et al. The brain microenvironment preferentially enhances the radioresistance of CD133(+) glioblastoma stem-like cells. Neoplasia. 2012;14(2):150-8.

63. Yoshida GJ, Saya H. Therapeutic strategies targeting cancer stem cells. Cancer Sci. 2016;107(1):5-11.

64. Khandia R, Dadar M, Munjal A, et al. A comprehensive review of autophagy and its various roles in infectious, non-infectious, and lifestyle diseases: current knowledge and prospects for disease prevention, novel drug design, and therapy. Cells. 2019;8(7):1-64.

65. Rouschop KM, van den Beucken $T$, Dubois $L$, et al. The unfolded protein response protects human tumor cells during hypoxia through regulation of the autophagy genes MAP 1LC3B and ATG5. J Clin Invest. 2010;120(1):127-41. 
66. Hou J, Han ZP, Jing YY, et al. Autophagy prevents irradiation injury and maintains stemness through decreasing ROS generation in mesenchymal stem cells. Cell Death Dis. 2013;4:e844.

67. Lomonaco SL, Finniss S, Xiang C, et al. The induction of autophagy by gamma-radiation contributes to the radioresistance of glioma stem cells. Int J Cancer. 2009;125(3):717-22.

68. Mitrakas AG, Kalamida D, Giatromanolaki A, et al. Autophagic flux response and glioblastoma sensitivity to radiation. Cancer Biol Med. 2018;15(3):260-74

69. Zhuang W, Li B, Long L, et al. Knockdown of the DNA-dependent protein kinase catalytic subunit radiosensitizes glioma-initiating cells by inducing autophagy. Brain Res. 2011;1371:7-15.

70. Liu $Y$, Shen $Y$, Sun $T$, et al. Mechanisms regulating radiosensitivity of glioma stem cells. Neoplasma. 2017;64(5):655-65.

71. Woo Y, Lee HJ, Jung YM, et al. mTOR-mediated antioxidant activation in solid tumor Radioresistance. J Oncol. 2019;2019:5956867.

72. Beier D, Schulz JB, Beier CP. Chemoresistance of glioblastoma cancer stem cells--much more complex than expected. Mol Cancer. 2011;10:128.

73. Ropolo M, Daga A, Griffero F, et al. Comparative analysis of DNA repair in stem and nonstem glioma cell cultures. Mol Cancer Res. 2009;7(3): 383-92.

74. Stupp R, Hegi ME, Mason WP, et al. Effects of radiotherapy with concomitant and adjuvant temozolomide versus radiotherapy alone on survival in glioblastoma in a randomised phase III study: 5-year analysis of the EORTC-NCIC trial. Lancet Oncol. 2009;10(5):459-66.

75. Hegi ME, Diserens AC, Gorlia T, et al. MGMT gene silencing and benefit from temozolomide in glioblastoma. N Engl J Med. 2005;352(10):9971003.

76. Chinot OL, Barrie M, Fuentes S, et al. Correlation between O6methylguanine-DNA methyltransferase and survival in inoperable newly diagnosed glioblastoma patients treated with neoadjuvant temozolomide. J Clin Oncol. 2007;25(12):1470-5.

77. Beier D, Rohrl S, Pillai DR, et al. Temozolomide preferentially depletes cancer stem cells in glioblastoma. Cancer Res. 2008;68(14):5706-15.

78. Liu G, Yuan X, Zeng Z, et al. Analysis of gene expression and chemoresistance of CD133+ cancer stem cells in glioblastoma. Mol Cancer. 2006;5:67.

79. Pistollato F, Abbadi S, Rampazzo E, et al. Intratumoral hypoxic gradient drives stem cells distribution and MGMT expression in glioblastoma. Stem Cells. 2010;28(5):851-62.

80. Auffinger B, Tobias AL, Han Y, et al. Conversion of differentiated cancer cells into cancer stem-like cells in a glioblastoma model after primary chemotherapy. Cell Death Differ. 2014;21(7):1119-31.

81. Anna Ciechomska I, Kocyk M, Kaminska B. Glioblastoma stem-like cellsisolation, biology and mechanisms of chemotherapy resistance. Curr Signal Transduct Ther. 2013:8(3):256-67.

82. Chua C, Zaiden N, Chong KH, et al. Characterization of a side population of astrocytoma cells in response to temozolomide. J Neurosurg. 2008;109(5): 856-66.

83. Nakai E, Park K, Yawata T, et al. Enhanced MDR1 expression and chemoresistance of cancer stem cells derived from glioblastoma. Cancer Investig. 2009;27(9):901-8.

84. Yamada K, Tso J, Ye F, et al. Essential gene pathways for glioblastoma stem cells: clinical implications for prevention of tumor recurrence. Cancers. 2011; 3(2):1975-95.

85. Schaich M, Kestel L, Pfirrmann M, et al. A MDR1 (ABCB1) gene single nucleotide polymorphism predicts outcome of temozolomide treatment in glioblastoma patients. Ann Oncol. 2009;20(1):175-81.

86. Bleau AM, Hambardzumyan D, Ozawa T, et al. PTEN/PI3K/Akt pathway regulates the side population phenotype and $A B C G 2$ activity in glioma tumor stem-like cells. Cell Stem Cell. 2009;4(3):226-35.

87. Martin V, Sanchez-Sanchez AM, Herrera F, et al. Melatonin-induced methylation of the ABCG2/BCRP promoter as a novel mechanism to overcome multidrug resistance in brain tumour stem cells. $\mathrm{Br} J$ Cancer. 2013;108(10):2005-12.

88. Tivnan A, Zakaria Z, O'Leary C, et al. Inhibition of multidrug resistance protein 1 (MRP1) improves chemotherapy drug response in primary and recurrent glioblastoma multiforme. Front Neurosci. 2015;9:218.

89. Hirose $Y$, Berger MS, Pieper RO. Abrogation of the Chk1-mediated G (2) checkpoint pathway potentiates temozolomide-induced toxicity in a p53- independent manner in human glioblastoma cells. Cancer Res. 2001;61(15): 5843-9.

90. Mhaidat NM, Zhang XD, Allen J, et al. Temozolomide induces senescence but not apoptosis in human melanoma cells. Br J Cancer. 2007;97(9):122533.

91. Hsieh A, Ellsworth R, Hsieh D. Hedgehog/GLI1 regulates IGF dependent malignant behaviors in glioma stem cells. J Cell Physiol. 2011;226(4):111827.

92. Eramo A, Ricci-Vitiani $L$, Zeuner A, et al. Chemotherapy resistance of glioblastoma stem cells. Cell Death Differ. 2006;13(7):1238-41.

93. Kanzawa T, Germano IM, Komata T, et al. Role of autophagy in temozolomide-induced cytotoxicity for malignant glioma cells. Cell Death Differ. 2004;11(4):448-57.

94. Yan $Y, X u Z$, Dai S, et al. Targeting autophagy to sensitive glioma to temozolomide treatment. J Exp Clin Cancer Res. 2016:35:23.

95. Fu J, Liu ZG, Liu XM, et al. Glioblastoma stem cells resistant to temozolomide-induced autophagy. Chin Med J. 2009:122(11):1255-9.

96. Zhuang $W$, Li B, Long L, et al. Induction of autophagy promotes differentiation of glioma-initiating cells and their radiosensitivity. Int J Cancer. 2011;129(11):2720-31.

97. Zhuang WZ, Long LM, Ji WJ, et al. Rapamycin induces differentiation of glioma stem/progenitor cells by activating autophagy. Chin J Cancer. 2011; 30(10):712-20.

98. Schonberg T, Bakkour A, Hover AM, et al. Changing value through cued approach: an automatic mechanism of behavior change. Nat Neurosci. 2014;17(4):625-30.

99. Ulasov IV, Nandi S, Dey M, et al. Inhibition of Sonic hedgehog and Notch pathways enhances sensitivity of CD133(+) glioma stem cells to temozolomide therapy. Mol Med. 2011;17(1-2):103-12.

100. Wellner U, Schubert J, Burk UC, et al. The EMT-activator ZEB1 promotes tumorigenicity by repressing stemness-inhibiting microRNAs. Nat Cell Biol. 2009:11(12):1487-95.

101. Siebzehnrubl FA, Silver DJ, Tugertimur B, et al. The ZEB1 pathway links glioblastoma initiation, invasion and chemoresistance. EMBO Mol Med. 2013;5(8):1196-212.

102. Hjelmeland $A B, W u Q$, Heddleston JM, et al. Acidic stress promotes a glioma stem cell phenotype. Cell Death Differ. 2011;18(5):829-40.

103. Villalva C, Martin-Lanneree S, Cortes $U$, et al. STAT3 is essential for the maintenance of neurosphere-initiating tumor cells in patients with glioblastomas: a potential for targeted therapy? Int J Cancer. 2011;128(4): 826-38.

104. McCord AM, Jamal M, Shankavaram UT, et al. Physiologic oxygen concentration enhances the stem-like properties of CD133+ human glioblastoma cells in vitro. Mol Cancer Res. 2009;7(4):489-97.

105. Chen R, Nishimura MC, Bumbaca SM, et al. A hierarchy of selfrenewing tumor-initiating cell types in glioblastoma. Cancer Cell. 2010;17(4):362-75.

106. Yakisich JS. Challenges and limitations of targeting cancer stem cells and/or the tumour microenvironment. Drugs Ther Stud. 2012;2(1):e10.

107. Hyun $\mathrm{KH}$, Yoon $\mathrm{CH}$, Kim RK, et al. Eckol suppresses maintenance of stemness and malignancies in glioma stem-like cells. Toxicol Appl Pharmacol. 2011;254(1):32-40.

108. Wang B, Yu SC, Jiang JY, et al. An inhibitor of arachidonate 5-lipoxygenase, Nordy, induces differentiation and inhibits self-renewal of glioma stem-like cells. Stem Cell Rev Rep. 2011;7(2):458-70.

109. Yang YP, Chang YL, Huang PI, et al. Resveratrol suppresses tumorigenicity and enhances radiosensitivity in primary glioblastoma tumor initiating cells by inhibiting the STAT3 axis. J Cell Physiol. 2012; 227(3):976-93.

110. Okamoto K, Ito D, Miyazaki K, et al. Microregional antitumor activity of a small-molecule hypoxia-inducible factor 1 inhibitor. Int J Mol Med. 2012 29(4):541-9.

111. Sai K, Wang S, Balasubramaniyan V, et al. Induction of cell-cycle arrest and apoptosis in glioblastoma stem-like cells by WP1193, a novel small molecule inhibitor of the JAK2/STAT3 pathway. J Neuro-Oncol. 2012;107(3):487-501.

112. Torquato HF, Goettert MI, Justo GZ, et al. Anti-Cancer Phytometabolites targeting Cancer stem cells. Curr Genomics. 2017;18(2):156-74.

113. Cho DY, Lin SZ, Yang WK, et al. Targeting cancer stem cells for treatment of glioblastoma multiforme. Cell Transplant. 2013:22(4):731-9. 
114. Dixit D, Ghildiyal R, Anto NP, et al. Guggulsterone sensitizes glioblastoma cells to sonic hedgehog inhibitor SANT-1 induced apoptosis in a Ras/ NFkappaB dependent manner. Cancer Lett. 2013;336(2):347-58.

115. Bates SE. Drugs that target the stemness pathways. Clin Cancer Res. 2010; 16(12):3105.

116. Curran T. Reproducibility of academic preclinical translational research: lessons from the development of Hedgehog pathway inhibitors to treat cancer. Open Biol. 2018;8(8):180098.

117. Che J, Zhang FZ, Zhao CQ, et al. Cyclopamine is a novel hedgehog signaling inhibitor with significant anti-proliferative, anti-invasive and antiestrogenic potency in human breast cancer cells. Oncol Lett. 2013;5(4): 1417-21.

118. Cochrane CR, Szczepny A, Watkins DN, et al. Hedgehog signaling in the maintenance of cancer stem cells. Cancers. 2015;7(3):1554-85.

119. Nitta RT, Gholamin S, Feroze AH, et al. Casein kinase 2alpha regulates glioblastoma brain tumor-initiating cell growth through the beta-catenin pathway. Oncogene. 2015;34(28):3688-99.

120. Liu X, Chen J, Li W, et al. Inhibition of casein kinase II by CX-4945, but not yes-associated protein (YAP) by verteporfin, enhances the antitumor efficacy of Temozolomide in Glioblastoma. Transl Oncol. 2020;13(1):70-8.

121. Pagano MA, Bain J, Kazimierczuk Z, et al. The selectivity of inhibitors of protein kinase CK2: an update. Biochem J. 2008;415(3):353-65.

122. Sharma V, Hupp CD, Tepe JJ. Enhancement of chemotherapeutic efficacy by small molecule inhibition of NF-kappaB and checkpoint kinases. Curr Med Chem. 2007;14(10):1061-74.

123. Bucher N, Britten CD. G2 checkpoint abrogation and checkpoint kinase-1 targeting in the treatment of cancer. Br J Cancer. 2008;98(3):523-8.

124. Chumsri S, Shah P. Radiation resistance of cancer stem cells as an obstacle in cancer therapy. Mol Cell Pharmacol. 2013;5(1):39-49.

125. Patties I, Kallendrusch S, Bohme L, et al. The Chk1 inhibitor SAR-020106 sensitizes human glioblastoma cells to irradiation, to temozolomide, and to decitabine treatment. J Exp Clin Cancer Res. 2019;38(1):420.

126. Zabludoff SD, Deng C, Grondine MR, et al. AZD7762, a novel checkpoint kinase inhibitor, drives checkpoint abrogation and potentiates DNAtargeted therapies. Mol Cancer Ther. 2008;7(9):2955-66.

127. Signore M, Pelacchi $F$, di Martino S, et al. Combined PDK1 and CHK1 inhibition is required to kill glioblastoma stem-like cells in vitro and in vivo. Cell Death Dis. 2014;5:e1223.

128. Facchino S, Abdouh M, Bernier G. Brain cancer stem cells: current status on glioblastoma multiforme. Cancers. 2011;3(2):1777-97.

129. Soeda A, Inagaki A, Oka N, et al. Epidermal growth factor plays a crucial role in mitogenic regulation of human brain tumor stem cells. J Biol Chem. 2008;283(16):10958-66.

130. Liffers K, Lamszus K, Schulte A. EGFR amplification and glioblastoma stemlike cells. Stem Cells Int. 2015;2015:427518.

131. Jun HJ, Bronson RT, Charest A. Inhibition of EGFR induces a c-MET-driven stem cell population in glioblastoma. Stem Cells. 2014;32(2):338-48.

132. Lima FR, Kahn SA, Soletti RC, et al. Glioblastoma: therapeutic challenges, what lies ahead. Biochim Biophys Acta. 2012;1826(2):338-49.

133. Fenton TR, Nathanson D, Ponte de Albuquerque C, et al. Resistance to EGF receptor inhibitors in glioblastoma mediated by phosphorylation of the PTEN tumor suppressor at tyrosine 240. Proc Natl Acad Sci U S A. 2012; 109(35):14164-9.

134. Kaza N, Kohli L, Roth KA. Autophagy in brain tumors: a new target for therapeutic intervention. Brain Pathol. 2012;22(1):89-98.

135. Murat A, Migliavacca E, Gorlia T, et al. Stem cell-related "self-renewal" signature and high epidermal growth factor receptor expression associated with resistance to concomitant chemoradiotherapy in glioblastoma. J Clin Oncol. 2008;26(18):3015-24.

136. Prados MD, Chang SM, Butowski N, et al. Phase II study of erlotinib plus temozolomide during and after radiation therapy in patients with newly diagnosed glioblastoma multiforme or gliosarcoma. J Clin Oncol. 2009;27(4): 579-84.

137. Pang LY, Saunders L, Argyle DJ. Epidermal growth factor receptor activity is elevated in glioma cancer stem cells and is required to maintain chemotherapy and radiation resistance. Oncotarget. 2017;8(42): 72494-512.

138. Zhang I, Beus M, Stochaj U, et al. Inhibition of glioblastoma cell proliferation, invasion, and mechanism of action of a novel hydroxamic acid hybrid molecule. Cell Death Discov. 2018;4:41.
139. Li X, Wu C, Chen N, et al. PI3K/Akt/mTOR signaling pathway and targeted therapy for glioblastoma. Oncotarget. 2016;7(22):33440-50.

140. Cloughesy TF, Yoshimoto K, Nghiemphu P, et al. Antitumor activity of rapamycin in a phase I trial for patients with recurrent PTEN-deficient glioblastoma. PLoS Med. 2008;5(1):e8,

141. Reardon DA, Desjardins A, Vredenburgh JJ, et al. Phase 2 trial of erlotinib plus sirolimus in adults with recurrent glioblastoma. J Neuro-Oncol. 2010; 96(2):219-30.

142. Chong DQ, Toh XY, Ho IA, et al. Combined treatment of Nimotuzumab and rapamycin is effective against temozolomide-resistant human gliomas regardless of the EGFR mutation status. BMC Cancer. 2015;15:255.

143. Folkins C, Man S, Xu P, et al. Anticancer therapies combining antiangiogenic and tumor cell cytotoxic effects reduce the tumor stem-like cell fraction in glioma xenograft tumors. Cancer Res. 2007;67(8):3560-4.

144. Campos B, Wan F, Farhadi M, et al. Differentiation therapy exerts antitumor effects on stem-like glioma cells. Clin Cancer Res. 2010;16(10):2715-28.

145. Yang L, Guo H, Dong $L$, et al. Tanshinone IIA inhibits the growth, attenuates the stemness and induces the apoptosis of human glioma stem cells. Oncol Rep. 2014;32(3):1303-11.

146. Manandhar B, Paudel P, Seong SH, et al. Characterizing Eckol as a therapeutic aid: a systematic review. Mar Drugs. 2019;17(6):1-31.

147. Yang X, Cui W, Yu S, et al. A synthetic dl-nordihydroguaiaretic acid (Nordy), inhibits angiogenesis, invasion and proliferation of glioma stem cells within a zebrafish xenotransplantation model. PLoS One. 2014;9(1):e85759.

148. de la lglesia N, Puram SV, Bonni A. STAT3 regulation of glioblastoma pathogenesis. Curr Mol Med. 2009;9(5):580-90.

149. Brastianos PK, Batchelor T. Vascular endothelial growth factor inhibitors in malignant gliomas. Target Oncol. 2010;5(3):167-74.

150. Javan MR, Khosrojerdi A, Moazzeni SM. New insights into implementation of mesenchymal stem cells in cancer therapy: prospects for anti-angiogenesis treatment. Front Oncol. 2019;9:840.

151. Binello E, Germano IM. Targeting glioma stem cells: a novel framework for brain tumors. Cancer Sci. 2011;102(11):1958-66.

152. Wenger JB, Santos N, Liu Y, et al. Can we develop effective combination antiangiogenic therapy for patients with hepatocellular carcinoma? Oncol Rev. 2011;5(3):177-84.

153. Cao Z, Fang J, Xia C, et al. Trans-3,4,5'-Trihydroxystibene inhibits hypoxiainducible factor 1alpha and vascular endothelial growth factor expression in human ovarian cancer cells. Clin Cancer Res. 2004;10(15):5253-63.

154. Choi H, Chun YS, Kim SW, et al. Curcumin inhibits hypoxia-inducible factorby degrading aryl hydrocarbon receptor nuclear translocator: a mechanism of tumor growth inhibition. Mol Pharmacol. 2006;70(5):1664-71.

155. Wojton J, Elder J, Kaur B. How efficient are autophagy inhibitors as treatment for glioblastoma? CNS Oncol. 2014;3(1):5-7.

156. Chresta CM, Davies BR, Hickson I, et al. AZD8055 is a potent, selective, and orally bioavailable ATP-competitive mammalian target of rapamycin kinase inhibitor with in vitro and in vivo antitumor activity. Cancer Res. 2010;70(1): 288-98.

157. Masliantsev K, Pinel B, Balbous A, et al. Impact of STAT3 phosphorylation in glioblastoma stem cells radiosensitization and patient outcome. Oncotarget. 2018:9(3):3968-79.

158. Hussain SF, Kong LY, Jordan J, et al. A novel small molecule inhibitor of signal transducers and activators of transcription 3 reverses immune tolerance in malignant glioma patients. Cancer Res. 2007;67(20):9630-6.

159. Martinez-Garcia M, Banerji U, Albanell J, et al. First-in-human, phase I doseescalation study of the safety, pharmacokinetics, and pharmacodynamics of RO5126766, a first-in-class dual MEK/RAF inhibitor in patients with solid tumors. Clin Cancer Res. 2012;18(17):4806-19.

160. Flannery PC, DeSisto JA, Amani V, et al. Preclinical analysis of MTOR complex 1/2 inhibition in diffuse intrinsic pontine glioma. Oncol Rep. 2018; 39(2):455-64.

161. Ashizawa T, Miyata H, lizuka A, et al. Effect of the STAT3 inhibitor STX-0119 on the proliferation of cancer stem-like cells derived from recurrent glioblastoma. Int J Oncol. 2013;43(1):219-27.

162. Mazurek M, Litak J, Kamieniak P, et al. Metformin as potential therapy for high-grade glioma. Cancers. 2020;12(1):1-29.

163. Nanegrungsunk D, Onchan W, Chattipakorn N, et al. Current evidence of temozolomide and bevacizumab in treatment of gliomas. Neurol Res. 2015; 37(2):167-83. 
164. Vredenburgh JJ, Desjardins A, Herndon JE 2nd, et al. Phase II trial of bevacizumab and irinotecan in recurrent malignant glioma. Clin Cancer Res. 2007;13(4):1253-9.

165. Hadjipanayis CG, Van Meir EG. Tumor initiating cells in malignant gliomas: biology and implications for therapy. J Mol Med. 2009;87(4):363-74.

166. Lim YC, Kang HJ, Kim YS, et al. All-trans-retinoic acid inhibits growth of head and neck cancer stem cells by suppression of Wnt/beta-catenin pathway. Eur J Cancer. 2012;48(17):3310-8.

167. Kim JE, Patel M, Ruzevick J, et al. STAT3 activation in glioblastoma: biochemical and therapeutic implications. Cancers. 2014;6(1):376-95.

168. Fujiwara Y, Komohara Y, Kudo R, et al. Oleanolic acid inhibits macrophage differentiation into the $M 2$ phenotype and glioblastoma cell proliferation by suppressing the activation of STAT3. Oncol Rep. 2011;26(6):1533-7.

169. Ball S, Li C, Li PK, et al. The small molecule, LLL12, inhibits STAT3 phosphorylation and induces apoptosis in medulloblastoma and glioblastoma cells. PloS one. 2011;6(4):e18820.

170. Chen JK, Taipale J, Cooper MK, et al. Inhibition of hedgehog signaling by direct binding of cyclopamine to smoothened. Genes Dev. 2002;16(21): 2743-8

171. McGee MC, Hamner JB, Williams RF, et al. Improved intratumoral oxygenation through vascular normalization increases glioma sensitivity to ionizing radiation. Int J Radiat Oncol Biol Phys. 2010;76(5):1537-45.

172. Li N, Maly DJ, Chanthery YH, et al. Radiotherapy followed by aurora kinase inhibition targets tumor-propagating cells in human glioblastoma. Mol Cancer Ther. 2015;14(2):419-28.

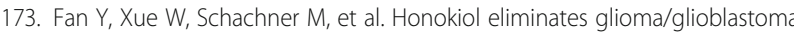
stem cell-like cells via JAK-STAT3 signaling and inhibits tumor progression by targeting epidermal growth factor receptor. Cancers. 2018;11(1):1-21.

174. Lin JW, Chen JT, Hong CY, et al. Honokiol traverses the blood-brain barrier and induces apoptosis of neuroblastoma cells via an intrinsic baxmitochondrion-cytochrome c-caspase protease pathway. Neuro Oncol. 2012;14(3):302-14

175. Crane C, Panner A, Pieper RO, et al. Honokiol-mediated inhibition of PI3K mTOR pathway: a potential strategy to overcome immunoresistance in glioma, breast, and prostate carcinoma without impacting $T$ cell function. J Immunother. 2009;32(6):585-92.

176. Lai IC, Shih PH, Yao CJ, et al. Elimination of cancer stem-like cells and potentiation of temozolomide sensitivity by Honokiol in glioblastoma multiforme cells. PLoS One. 2015;10(3):e0114830.

177. Aguado T, Carracedo A, Julien B, et al. Cannabinoids induce glioma stemlike cell differentiation and inhibit gliomagenesis. J Biol Chem. 2007;282(9): 6854-62.

178. Lee J, Son MJ, Woolard K, et al. Epigenetic-mediated dysfunction of the bone morphogenetic protein pathway inhibits differentiation of glioblastoma-initiating cells. Cancer Cell. 2008;13(1):69-80.

179. Xi G, Best B, Mania-Farnell B, et al. Therapeutic potential for bone morphogenetic protein 4 in human malignant glioma. Neoplasia. 2017; 19(4):261-70.

180. Piccirillo SG, Reynolds BA, Zanetti N, et al. Bone morphogenetic proteins inhibit the tumorigenic potential of human brain tumour-initiating cells. Nature. 2006:444(7120):761-5.

181. Lopez-Valero I, Saiz-Ladera C, Torres S, et al. Targeting Glioma Initiating Cells with A combined therapy of cannabinoids and temozolomide. Biochem Pharmacol. 2018;157:266-74.

182. Taddei A, Roche D, Bickmore WA, et al. The effects of histone deacetylase inhibitors on heterochromatin: implications for anticancer therapy? EMBO Rep. 2005;6(6):520-4

183. Soliman ML, Smith MD, Houdek HM, et al. Acetate supplementation modulates brain histone acetylation and decreases interleukin-1beta expression in a rat model of neuroinflammation. J Neuroinflammation. 2012 9:51.

184. Kim S, Chen J, Cheng T, et al. PubChem 2019 update: improved access to chemical data. Nucleic Acids Res. 2019:47(D1):D1102-9.

185. Bar EE, Chaudhry A, Lin A, et al. Cyclopamine-mediated hedgehog pathway inhibition depletes stem-like cancer cells in glioblastoma. Stem Cells. 2007 25(10):2524-33.

186. Son YH, Song JS, Kim SH, et al. Pharmacokinetic characterization of CK2 inhibitor CX-4945. Arch Pharm Res. 2013;36(7):840-5.

187. Firat E, Weyerbrock A, Gaedicke S, et al. Chloroquine or chloroquine-PI3K Akt pathway inhibitor combinations strongly promote gamma-irradiation- induced cell death in primary stem-like glioma cells. PLoS One. 2012;7(10): e47357.

188. Weyerhauser P, Kantelhardt SR, Kim EL. Re-purposing chloroquine for glioblastoma: potential merits and confounding variables. Front Oncol. 2018;8:335.

189. Buccarelli M, Marconi M, Pacioni S, et al. Inhibition of autophagy increases susceptibility of glioblastoma stem cells to temozolomide by igniting ferroptosis. Cell Death Dis. 2018;9(8):841.

190. Lomonaco SL, Finniss S, Xiang C, et al. Cilengitide induces autophagymediated cell death in glioma cells. Neuro-oncology. 2011;13(8):857-65.

191. Kahn J, Hayman TJ, Jamal M, et al. The mTORC1/mTORC2 inhibitor AZD2014 enhances the radiosensitivity of glioblastoma stem-like cells. Neuro Oncol. 2014:16(1):29-37.

192. Akhavan D, Cloughesy TF, Mischel PS. mTOR signaling in glioblastoma: lessons learned from bench to bedside. Neuro-oncology. 2010;12(8):882-9.

193. Cilibrasi C, Riva G, Romano G, et al. Resveratrol impairs glioma stem cells proliferation and motility by modulating the Wnt signaling pathway. PLoS One. 2017;12(1):e0169854.

194. Hussain Al, Anwar F, Rasheed S, et al. Composition, antioxidant and chemotherapeutic properties of the essential oils from two Origanum species growing in Pakistan. Rev Bras. 2011;21(6):943-52.

195. Roodink I, Leenders WP. Targeted therapies of cancer: angiogenesis inhibition seems not enough. Cancer Lett. 2010;299(1):1-10.

196. Arbab AS. Activation of alternative pathways of angiogenesis and involvement of stem cells following anti-angiogenesis treatment in glioma. Histol Histopathol. 2012;27(5):549-57.

197. Morris PG. Bevacizumab is an active agent for recurrent high-grade glioma, but do we need randomized controlled trials? Anti-Cancer Drugs. 2012; 23(6):579-83.

198. Zhong XS, Zheng JZ, Reed E, et al. SU5416 inhibited VEGF and HIF-1alpha expression through the PI3K/AKT/p70S6K1 signaling pathway. Biochem Biophys Res Commun. 2004:324(2):471-80.

199. Hossain M, Banik NL, Ray SK. Synergistic anti-cancer mechanisms of curcumin and paclitaxel for growth inhibition of human brain tumor stem cells and LN18 and U138MG cells. Neurochem Int. 2012;61(7):1102-13.

200. Ivanov VN, Wu J, Wang TJC, et al. Inhibition of ATM kinase upregulates levels of cell death induced by cannabidiol and gamma-irradiation in human glioblastoma cells. Oncotarget. 2019;10(8):825-46.

201. Persano L, Pistollato F, Rampazzo E, et al. BMP2 sensitizes glioblastoma stem-like cells to temozolomide by affecting HIF-1alpha stability and MGMT expression. Cell Death Dis. 2012;3:e412.

202. Massard C, Deutsch E, Soria JC. Tumour stem cell-targeted treatment: elimination or differentiation. Ann Oncol. 2006;17(11):1620-4.

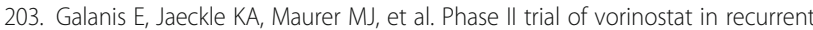
glioblastoma multiforme: a north central cancer treatment group study. J Clin Oncol. 2009;27(12):2052-8.

204. Sung GJ, Kim SH, Kwak S, et al. Inhibition of TFEB oligomerization by cotreatment of melatonin with vorinostat promotes the therapeutic sensitivity in glioblastoma and glioma stem cells. J Pineal Res. 2019:66(3):e12556.

205. Zhou Q, Dalgard CL, Wynder C, et al. Histone deacetylase inhibitors SAHA and sodium butyrate block G1-to-S cell cycle progression in neurosphere formation by adult subventricular cells. BMC Neurosci. 2011;12:50.

206. Ying $M$, Wang $S$, Sang $Y$, et al. Regulation of glioblastoma stem cells by retinoic acid: role for Notch pathway inhibition. Oncogene. 2011;30(31): 3454-67.

207. Das A, Banik NL, Ray SK. Molecular mechanisms of the combination of retinoid and interferon-gamma for inducing differentiation and increasing apoptosis in human glioblastoma T98G and U87MG cells. Neurochem Res. 2009;34(1):87-101.

208. Guan K, Chang H, Rolletschek A, et al. Embryonic stem cell-derived neurogenesis. Retinoic acid induction and lineage selection of neuronal cells. Cell Tissue Res. 2001:305(2):171-6.

209. Karmakar S, Choudhury SR, Banik NL, et al. Combination of N-(4hydroxyphenyl) retinamide and genistein increased apoptosis in neuroblastoma SK-N-BE2 and SH-SY5Y xenografts. Neuroscience. 2009; 163(1):286-95.

210. Karsy M, Albert L, Tobias ME, et al. All-trans retinoic acid modulates cance stem cells of glioblastoma multiforme in an MAPK-dependent manner. Anticancer Res. 2010;30(12):4915-20.

211. Carol H, Boehm I, Reynolds CP, et al. Efficacy and pharmacokinetic pharmacodynamic evaluation of the aurora kinase A inhibitor MLN8237 
against preclinical models of pediatric cancer. Cancer Chemother Pharmacol. 2011;68(5):1291-304.

212. Lehman NL, O'Donnell JP, Whiteley $L$, et al. Aurora a is differentially expressed in gliomas, is associated with patient survival in glioblastoma and is a potential chemotherapeutic target in gliomas. Cell Cycle. 2012;11(3): 489-502.

213. Mannino M, Gomez-Roman N, Hochegger H, et al. Differential sensitivity of glioma stem cells to aurora kinase A inhibitors: implications for stem cell mitosis and centrosome dynamics. Stem Cell Res. 2014;13(1):135-43.

214. Ansari MF, Hayat F, Inam A, et al. New antiprotozoal agents: synthesis and biological evaluation of different 4-(7-chloroquinolin-4-yl) piperazin-1yl)pyrrolidin-2-yl) methanone derivatives. Bioorg Med Chem Lett. 2017;27(3): 460-465.

215. Hong X, O'Donnell JP, Salazar CR, et al. The selective aurora-A kinase inhibitor MLN8237 (alisertib) potently inhibits proliferation of glioblastoma neurosphere tumor stem-like cells and potentiates the effects of temozolomide and ionizing radiation. Cancer Chemother Pharmacol. 2014; 73(5):983-90.

216. Zumbar CT, Usubalieva A, King PD, et al. The CNS penetrating taxane TPI 287 and the AURKA inhibitor alisertib induce synergistic apoptosis in glioblastoma cells. J Neuro-Oncol. 2018;137(3):481-92.

217. Kogiso M, Qi L, Braun FK, et al. Concurrent inhibition of neurosphere and monolayer cells of pediatric glioblastoma by aurora A inhibitor MLN8237 predicted survival extension in PDOX models. Clin Cancer Res. 2018;24(9): 2159-70.

218. Emami Riedmaier A, Fisel P, Nies AT, et al. Metformin and cancer: from the old medicine cabinet to pharmacological pitfalls and prospects. Trends Pharmacol Sci. 2013;34(2):126-35.

219. Quinn BJ, Kitagawa H, Memmott RM, et al. Repositioning metformin for cancer prevention and treatment. Trends Endocrinol Metab. 2013;24(9):46980.

220. Isakovic A, Harhaji L, Stevanovic D, et al. Dual antiglioma action of metformin: cell cycle arrest and mitochondria-dependent apoptosis. Cell Mol Life Sci. 2007;64(10):1290-302.

221. Wurth R, Pattarozzi A, Gatti M, et al. Metformin selectively affects human glioblastoma tumor-initiating cell viability: a role for metformin-induced inhibition of Akt. Cell Cycle. 2013;12(1):145-56.

222. Sato A, Sunayama J, Okada M, et al. Glioma-initiating cell elimination by metformin activation of FOXO3 via AMPK. Stem Cells Transl Med. 2012;1(11): $811-24$.

223. Sunayama J, Sato A, Matsuda K, et al. FoxO3a functions as a key integrator of cellular signals that control glioblastoma stem-like cell differentiation and tumorigenicity. Stem Cells. 2011;29(9):1327-37.

224. Najbauer J, Kraljik N, Nemeth P. Glioma stem cells: markers, hallmarks and therapeutic targeting by metformin. Pathol Oncol Res. 2014;20(4):789-97.

225. Marucci C, Fumagalli G, Calogero F, et al. Natural products and cancer stem cells. Curr Pharm Des. 2015;21(38):5547-57.

226. Wang R, Liu C. All-trans retinoic acid therapy induces asymmetric division of glioma stem cells from the U87MG cell line. Oncol Lett. 2019;18(4):3646-54.

227. Miyazaki T, Pan Y, Joshi K, et al. Telomestatin impairs glioma stem cell survival and growth through the disruption of telomeric G-quadruplex and inhibition of the proto-oncogene, c-Myb. Clin Cancer Res. 2012;18(5):126880.

228. Nakamura T, Okabe S, Yoshida $\mathrm{H}$, et al. Targeting glioma stem cells in vivo by a G-quadruplex-stabilizing synthetic macrocyclic hexaoxazole. Sci Rep. 2017;7(1):3605

229. Liu H, Han D, Liu Y, et al. Harmine hydrochloride inhibits Akt phosphorylation and depletes the pool of cancer stem-like cells of glioblastoma. J Neuro-Oncol. 2013;112(1):39-48.

\section{Publisher's Note}

Springer Nature remains neutral with regard to jurisdictional claims in published maps and institutional affiliations. 